\title{
Smad proteins act in combination with synergistic and antagonistic regulators to target Dpp responses to the D rosophila mesoderm
}

\author{
Xiaolei Xu, ${ }^{1}$ Zhizhang Yin, $^{1}$ John B. Hudson, ${ }^{2}$ Edwin L. Ferguson, ${ }^{2}$ and Manfred Frasch ${ }^{1,3}$ \\ ${ }^{1}$ Brookdale Center for Developmental and Molecular Biology, M ount Sinai School of Medicine, N ew York, N ew York 10029 \\ USA; ${ }^{2}$ Department of Molecular Genetics and Cell Biology, University of Chicago, Chicago, Illinois 60637 USA
}

\begin{abstract}
Dorsal mesoderm induction in arthropods and ventral mesoderm induction in vertebrates are closely related processes that involve signals of the BMP family. In D rosophila, induction of visceral mesoderm, dorsal muscles, and the heart by Dpp is, at least in part, effected through the transcriptional activation and function of the homeobox gene tinman in dorsal mesodermal cells during early embryogenesis. Here we present a functional dissection of a tinman enhancer that mediates the Dpp response. We provide evidence that mesoderm-specific induction of tinman requires the binding of both activators and repressors. Screens for binding factors yielded Tinman itself and the Smad4 homolog Medea. We show that the binding and synergistic activities of Smad and Tinman proteins are critical for mesodermal tinman induction, wherees repressor binding sites prevent induction in the dorsal ectoderm and amnioserosa. Thus, integration of positive and negative regulators on enhancers of target genes appears to be an important mechanism in tissue-specific induction by TGF- $\beta$ molecules.
\end{abstract}

[Key Words: mesoderm induction; tinman; dpp; Medea; Mad; Smad; signal transduction; enhancer]

Received May 11, 1998; revised version accepted June 9, 1998.

Induction across germ layers is a key mechanism in controlling morphogenesis in a wide variety of developmental systems. Whereas a number of signaling molecules have recently been identified, most of the molecular events governing cell fate decisions during inductive processes are still unknown. For example, many signaling molecules are involved in a diverse range of inductive events during devel opment, but we know little about the mechanisms that provide specific target tissues with the competence to respond to these signals in an exquisite fashion. Moreover, we do not have much insight into what prevents a signaling tissue from being driven into the same developmental pathway as its target tissue.

D pp, a member of the TGF- $\beta$ superfamily (Padgett et al. 1987), is a well-studied signaling molecule that fulfills several critical roles during the devel opment of Drosophila. At blastoderm, decapentaplegic (dpp) mRN A is expressed along the dorsal $\sim 40 \%$ of the embryonic circumference, and its products determine different dorsal cell fates in a dose-dependent manner (St Johnston and Gel bart 1987). Peak levels of dpp activity are required to determine amnioserosa dorsally, whereas lower activities prevent neurogenesis in adjacent areas and al low for-

${ }^{3}$ Corresponding author.

E-MAIL frasch@msvax.mssm.edu; FAX (212) 860-9279. mation of dorsal ectoderm (Ferguson and Anderson 1992; Wharton et al. 1993; for review, see Bier 1997). At midembryogenesis, dpp is expressed in a portion of the visceral mesoderm, where it regulates midgut morphogenesis by inducing homeotic gene expression within the visceral mesoderm and across germ layers in the adjacent endoderm (for review, see Bienz 1994). During metamorphosis, dpp is expressed in precisely defined areas of the imaginal discs and is essential for growth and morphogenesis of the eyes and appendages (for review, see $\mathrm{N}$ eumann and Cohen 1997). It appears that different sets of downstream genes are activated during each of these phases of Dpp-mediated induction, some of them in a concentration-dependent fashion, but it is not clear how this specificity is achieved.

The induction of dorsal mesoderm is an additional important function of dpp and is the focus of this study. This event occurs after gastrulation, when dpp is expressed in the dorsal ectoderm and induces the underlying mesoderm to form heart, visceral musculature, and dorsal types of body wall muscles (Staehling-Hampton et al. 1994; Frasch 1995; Y in and Frasch 1998). It has been shown that tinman, a homeobox gene of the N K family, is a pivotal effector gene downstream of $\mathrm{dpp}$ in dorsal mesoderm induction. Similar to dpp, tinman is critically required for the formation of dorsal mesodermal deriva- 
tives, including the heart, visceral mesoderm, and dorsal somatic muscles (Azpiazu and Frasch 1993; Bodmer 1993). This role of tinman is reflected in its dynamic expression during early embryogenesis, which can be divided into two distinct phases. During its initial phase at gastrulation, tinman expression is activated by the bHLH protein Twist in a cell-autonomous fashion in the entire trunk mesoderm (Bodmer et al. 1990; Yin et al. 1997). Importantly, upon the spreading of the mesodermal layer after gastrulation, this broad mesodermal expression of tinman gives way to a pattern of spatially restricted expression in the dorsal portion of the mesoderm. This specific "maintenance" of tinman expression in the dorsal mesoderm is induced by Dpp signals from the dorsal ectoderm and is thought to be of major importance in the execution of dorsal mesoderm induction (Frasch 1995). Transduction of these signals requires the type I Dpp receptor Thickveins (Tkv; Brummel et al. 1994; Nellen et al. 1994; Penton et al. 1994; Yin and Frasch 1998), and the temporal sequence of events indicates that the tinman gene may be a direct target of dpp-dependent signaling components in the responding mesodermal cells.

How does dpp induce tinman expression specifically in the dorsal mesoderm but not in the dorsal ectoderm or in other tissues that receive dpp signal s? Functional dissection of genomic regions from the tinman locus has shown that the early phases of tinman expression are driven by two distinct enhancer elements (Yin et al. 1997). The first appears to be a Twist response el ement, as it is active during gastrulation in the entire trunk mesoderm and contains essential Twist binding sites. In contrast, the second enhancer is active in subsequent stages and only in the dorsal mesoderm, thus indicating that this enhancer functions as a D pp response el ement. These results suggest that Dpp induction triggers a second, spatially restricted round of transcriptional activation of tinman at the time when the first Twist-activated phase of expression ceases. This would provide an explanation for the dpp-dependent maintenance of tinman expression in the dorsal mesoderm.

Here we have undertaken a functional analysis of the 350-bp D pp response element and performed screens to identify DNA-binding proteins that mediate the Dpp response. We show that tinman autoregulation plays an important role in the D pp response, and that the synergy between Tinman and Dpp is conferred by two Tinman binding sites in the Dpp response element. We further identified two $\sim 30$-bp sequences within the Dpp response element, both of which are necessary for its activity, and used one of them to isolate cDNAs encoding specific DN A-binding factors. This screen resulted in the isolation of Medea, a Drosophila homolog of Smad4. Medea has been shown to act genetically downstream of dpp (Raftery et al. 1995; Hudson et al. 1998), and other studies have demonstrated that Smad proteins serve as effector proteins of TGF- $\beta$-rel ated signals (for review, see Heldin et al. 1997). We show herein that the tinman Dpp response element contains several in vitro binding sites for M edea and M ad, a pathway-restricted member of the
Smad family (Sekelsky et al. 1995), that are essential for its activity in vivo. Interestingly, the Dpp response ele ment also contains negatively acting sequences that prevent its activation in the dorsal ectoderm and amniose rosa. Together, our results suggest that specific induction of tinman is achieved through a combination of synergistic activities of Tinman and activated Smad proteins that elevate tinman expression in the dorsal mesoderm and repressor molecules that prevent tinman from being activated in the signaling tissue. Thus, it appears that integration of positive and negative regulation on the promoter level of target genes is an important aspect of tissue-specific induction events.

\section{Results}

tin-D, an evolutionarily conserved Dpp response element from the tinman gene

Functional dissection of the tinman gene identified a 349-bp enhancer in 3 -flanking regions, tin-D, that is strictly active in dorsal portions of the mesoderm of stage 10-11 embryos (Y in et al. 1997). The pattern of lacZ reporter gene expression driven by tin-D closely resembles the dpp-dependent pattern of endogenous tinman expression (Fig. 1A,B; Frasch 1995), thus suggesting that tin-D functions as a Dpp response element. This notion was further supported by the observation that tin-D reporter gene activity is absent in embryos with a dpp null mutant background (Fig. 1C). Conversely, upon ectopic expression of a constitutively active DPP type I receptor, $\mathrm{Tkv}^{\mathrm{Q}-\mathrm{D}}$, in the entire mesoderm, tin-D reporter gene expression expands into the ventral mesoderm (Fig. 1D). The observed changes of tin-D activity upon altering the levels and spatial extents of Dpp signaling closely reflect the changes seen for tinman expression under the same conditions (Frasch 1995; Yin and Frasch 1998). These observations raise the possibility that the tin-D enhancer is receiving direct inputs from the Dpp signal transduction cascade to activate tinman transcription. We also find that in addition to its dependence on dpp, dorsal mesodermal tinman expression requires the activity of tinman itself, as tinman mutant embryos show strongly reduced expression (Fig. 1E). Correspondingly, full activity of the tin-D enhancer depends on the function of tinman as well (Fig. 1F). Taken together, these results suggest that $D p p$ signals and autoregulation by tinman cooperate to induce full levels of tin-D enhancer activity and tinman expression in the dorsal mesoderm.

Sequence comparisons between the tin-D elements from Drosophila melanogaster and Drosophila virilis, which displayed identical activities in D. melanogaster embryos (Yin and Frasch 1998), show a high degree of sequence similarity (Fig. 1G), whereas the similarities in the $5^{\prime}$ - and 3 '-flanking regions of tin-D elements are considerably lower (data not shown). The strong sequence conservation between the tin-D enhancers from the two species could reflect the functional conservation of important regulatory sequences. A first inspection of the conserved sequences reveals several candidates for regu- 
Figure 1. In vivo activity, regulation, and sequence of the Dpp response element tin-D. Shown are cross sections through stage 10-11 embryos. (A) tinman mRNA expression in dorsal mesoderm of wild-type embryo. (B) tin-D/ lacZ expression in dorsal mesoderm of wild-type embryo. (C) tin-D/lacZ expression in $\mathrm{dpp}^{\mathrm{H} 46}$ homozygous mutant embryo. (D) tin-D/lacZ expression in an embryo with ectopic mesodermal expression of $\mathrm{Tkv}^{\mathrm{Q}-\mathrm{D}}$. (E) tinman mRNA expression in $\operatorname{tin}^{346}$ homozygous mutant embryo. Arrowheads delimit a domain with strongly reduced levels of tinman mRNA. (F) Strongly reduced tin-D/lacZ expression (arrowheads) in $\operatorname{tin}^{346}$ homozygous mutant embryo. Even-skipped (in neuronal cells; see arrow) was used to identify tin $^{-}$embryos; (G) Sequence alignment of tin-D elements from $D$. melanogaster and D. virilis. Identical sequences are boxed. Shaded sequences correspond to consensus binding sites for NK homeodomain proteins; sequences in reverse type are tandemly repeated motifs. (D1-D6) Sequences that were functionally tested in subsequent deletion experiments.
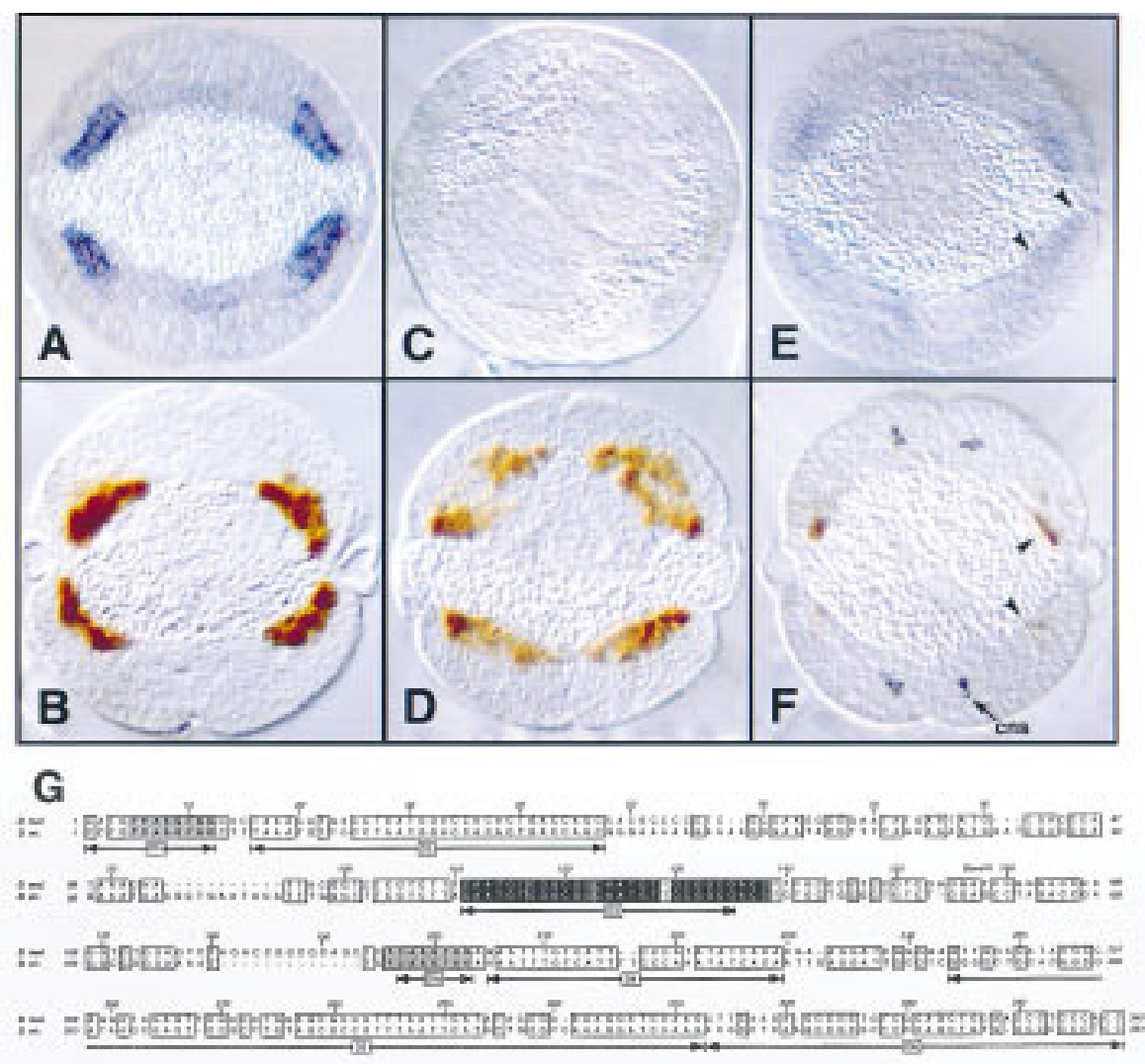

latory sites. One of them is a sequence that is present in duplicate, TCAAGTGG, which contains a binding site consensus for homeodomain proteins of the NK family and is identical to previously identified Tinman binding sequences from a heart enhancer of the D rosophila mef2 gene (Fig. 1G, shaded boxes) (Chen and Schwartz 1995; Damante et al. 1996; Gajewski et al. 1997). As demonstrated below, the Tinman protein has specific binding affinity to these sequences in vitro. Another completely conserved sequence is potentially interesting because it contains tandemly repeated CAATGT motifs, with each of the two copies being followed by a stretch of GC-rich sequences at their $3^{\prime}$ ends (Fig. 1G, black boxes).

tin-D includes sequences for induction, autoregulation, and ectodermal repression of tin

To define essential regulatory sequences within the tin-D enhancer, we generated a series of derivatives with various deletions of the most strongly conserved sequence blocks and tested their activity in vivo. Three of these fine deletions, $\Delta D 2, \Delta D 4$, and $\Delta D 5$, do not affect lacZ reporter gene expressi on in transgenic embryos (Fig. 1G; data not shown). This indicates that the deleted sequences (nucl eotide 16-47, 205-229, and 244-312) either lack any regulatory potential or contain functionally redundant regulatory sequences. In contrast, two other deletions result in a strong reduction of enhancer activity. One of them encompasses the tandemly repeated CAATGT/GC motifs ( $\triangle D 3$; Fig. $1 G$ ) and causes an al- most complete loss of enhancer activity (Fig. 2A). The other, $\Delta \mathrm{D} 6$, which del etes $30 \mathrm{bp}$ from the $3^{\prime}$ end of tin-D, also yields strongly reduced activity in the dorsal mesoderm (Fig. 2B). These results show that the subel ements D 3 and D6 contain important regulatory sequences for the induction of tinman in the dorsal mesoderm and thus are candidates for target sites of the Dpp signaling cascade.

To test whether the putativetinman binding sites play roles in autoregulation, we analyzed the activity of a tin-D derivative, tin-D- $\Delta \mathrm{D} 1$, in which both of these sites were deleted (nucleotide 1-13 and 197-203; Fig. 1G). As shown in Figure 2C, deletion of these sites provoked two interesting effects. The first is a significant reduction of lacZ reporter gene expression in the mesoderm, which indicates that tinman autoregulation is required to achieve full levels of dorsal mesodermal tinman induction through these sequences. A second, more unexpected effect is observed in the ectoderm. Specifically, embryos carrying tin-D- $\Delta \mathrm{D} 1$ show strong ectopic reporter gene expression in the dorsal ectoderm, which corresponds to the areas of dpp expression at this stage of development (Fig. 2C). Accordingly, in a dpp mutant background, both the ectodermal and the residual mesodermal activities of this mutant el ement are absent (data not shown). These results show that upon deletion of the tinman binding sites, tin-D is still able to respond to dpp, but its response is essentially switched from the target tissue to the signaling tissue. Therefore, we conclude that in the normal situation, Tinman binding to 


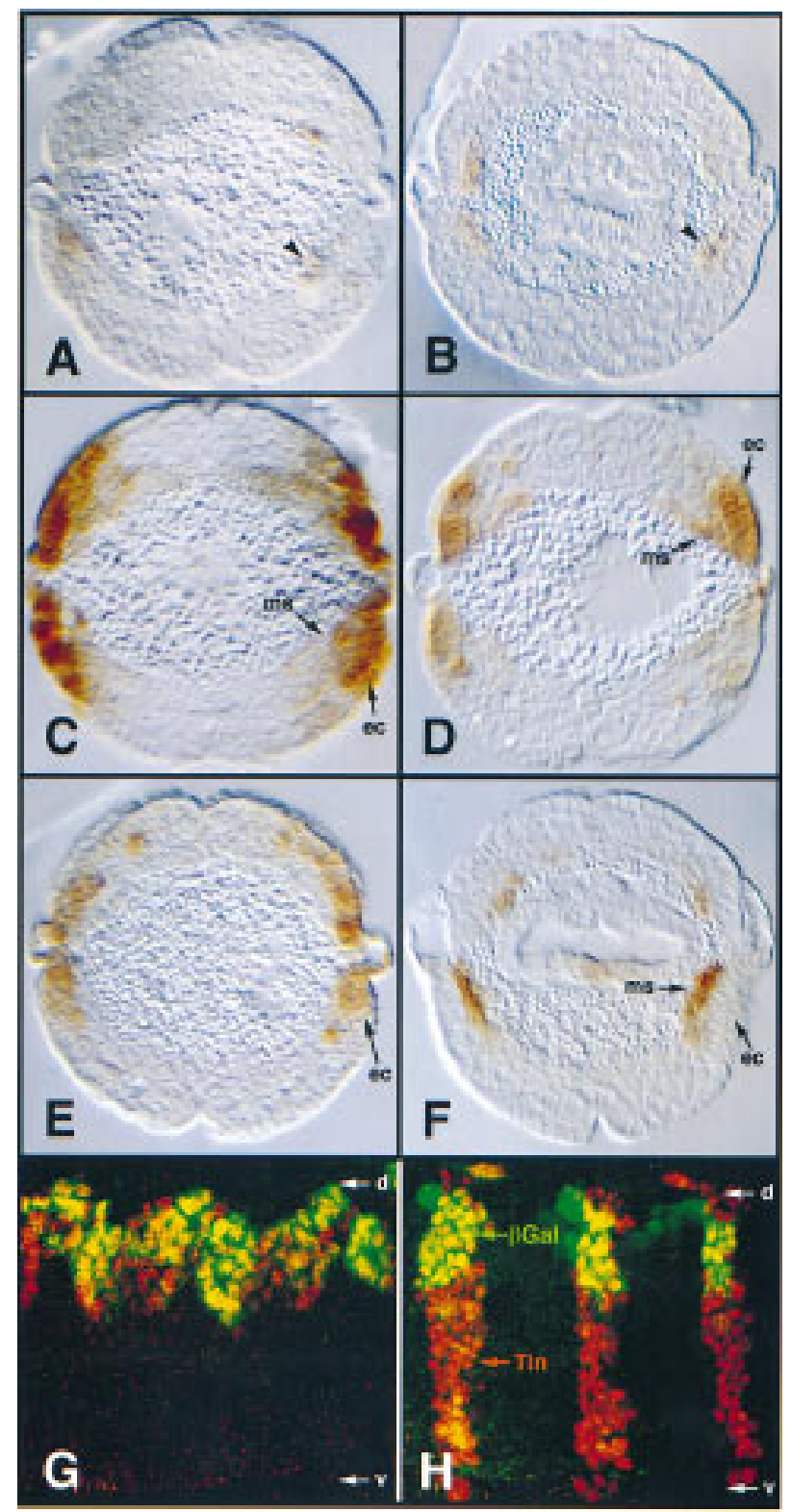

these sites is required in an autoregulatory fashion for full induction of tinman by the Dpp signal s in the dorsal mesoderm. In addition, the Tinman binding sites appear to overlap with binding sites for an unknown repressor that normally prevents induction of tinman in the dorsal ectoderm, and these two mechanisms together apparently ensure the mesoderm-specific response to Dpp.

The results of additional experiments, using combinations or multiple copies of the functionally important elements D1, D3, and D6, provide further support for this proposed mechanism. A construct containing five copies of D3 and four of D6 is capable of driving reporter gene expression in the dorsal ectoderm and, more weakly, in the dorsal mesoderm (Figs. 2D and 6, below). This pattern is very similar to the one observed for the tin-D enhancer construct lacking the tinman binding
Figure 2. Identification of functionally important sequences within tin-D and ectopic tin-D activation by tinman. tin-D$\Delta \mathrm{D} 3(\mathrm{~A})$ and tin-D- $\Delta \mathrm{D} 6(\mathrm{~B})$ are unable to drive significant levels of reporter gene expression (see arrowheads). (C) tin-D- $\Delta \mathrm{D} 1$ displays strongly reduced activity in the mesoderm and ectopic activity in the dorsal ectoderm. (D) Five copies of tin-D3 together with four copies of tin-D6 drive reporter gene expression in the dorsal ectoderm and weakly in the dorsal mesoderm. Stronger tin-D activity in the ectoderm as compared to the mesoderm could be due to higher ectodermal levels of D pp. (E) Five copies of tin-D3 are sufficient to drive reporter gene expression in the dorsal ectoderm, but only very weakly in the dorsal mesoderm. (F) Five copies of tin-D3 with the addition of two Tinman binding sites (tin-D1) drive reporter gene expression in a nearly normal pattern in the dorsal mesoderm. (G) Confocal laser scans of wild-type embryo that carried tin-D/lacZ and was stained with antibodies against Tinman (red signals) and $\beta$-gal (green signals). Tin and $\beta$-gal proteins are coexpressed in the dorsal mesoderm. $(\mathrm{H})$ Stage 10 embryo carrying tin-D/lacZ with ectopic ectodermal expression of tinman (tin-D/+; en-GAL4; UAS-tin). Confocal z-axis was set to include ectoderm only. Tinman is expressed in ectodermal stripes resembling the engrailed pattern, and $\beta$-gal expression is activated ectopically in dorsal ectodermal cells that contain tinman. (ms) Mesoderm; (ec) ectoderm; (d) dorsal; (v) ventral.

sites (tin-D- $\Delta \mathrm{D} 1$; see Fig. $2 \mathrm{C}$ ), al though the expression levels are lower. Importantly, a construct with just five copies of D3 (see M aterials and M ethods) is al so capable of activating reporter gene expression in the dorsal ectoderm, although expression levels are further reduced and expression is barely detectable in the mesoderm (Figs. 2E and 6). In contrast, multiple copies of D6 fail to activate reporter gene expression (data not shown). These results define the 32-bp (internally repeated) D3 sequence as a minimal Dpp response element. In addition, because multiple copies of the tinman binding sequence (D1) do not activate lacZ in the dorsal mesoderm, it appears that autoregulation requires $\mathrm{D}$ pp inputs for activation of gene expression (data not shown). Consistent with this view, we can reconstitute an al most normal pattern of reporter gene expression in the dorsal mesoderm by combining 
multiple copies of the Tinman binding sequence $D 1$ and the minimal Dpp response element D3 (Figs. 2F and 6).

In the normal situation, tinman autoregulation appears to be restricted to the mesoderm, presumably be cause the early, twist-activated phase of tinman expression is mesoderm specific. To test whether tinman is also able to autoregulate in the ectoderm, we expressed tinman ectopically and examined tin-D reporter gene expression under these conditions. For this purpose, tinman was expressed with the binary UAS/GAL4 system in ectodermal stripes under the control of an engrailed driver. As shown in Figure $2 \mathrm{H}$, ectodermally expressed tinman is capable of activating tin-D in the ectoderm (cf. with the wild type situation in Fig. 2G). Interestingly, ectodermal tin-D expression is restricted to dorsal portions of the transverse Tinman stripes, thereby demonstrating that tinman autoregulation can occur both in the mesoderm and in the ectoderm, but only in conjunction with Dpp signaling.

Essential tin-D sequences bind Tinman and the Smad proteins Medea and Mad

Because a combination of tin-D1 and tin-D 3 sequences is sufficient to reproduce a virtually normal expression pattern in the dorsal mesoderm, they appear to contain DNA sequences that can bind the essential factors involved in this inductive process. To identify some of these factors molecularly we used the yeast one-hybrid system to screen for Drosophila cDN As encoding proteins that specifically bind to D1 or D3 sequences (see $M$ aterials and Methods). Of note, when using multimeric D1 sequences as a bait, the only two clones that remained positive after the rescreens encoded Tinman protein sequences fused in-frame to the GAL4 activation domain (GAL4 AD). Because no other members of the homeobox gene family were isolated, this result further supports our notion that D1 sequences represent functional Tinman binding sites.

Importantly, with multimeric D3 sequences as a bait we isolated GAL4 AD fusion CDNAs that contained sequences with strong similarities to DPC4/Smad4 proteins, which have been described previously as effectors of various TGF- $\beta$ signaling processes. Of 54 candidate yeast clones, 8 carried these sequences and were derived from the same gene. Subsequent sequence comparisons showed that these cDNAs correspond to the Medea gene, which was isol ated independently by a genetic approach (Das et al. 1998; Hudson et al. 1998; Wisotzkey et al. 1998). Conceptual translation and sequence alignments with other members of this protein family indicate that the encoded GAL4 fusion proteins contain the complete amino-terminal portion of $M$ edea but lack the carboxy-terminal portion encoded by sequences $3^{\prime}$ to a native $\mathrm{N}$ otl site. It is concei vable that our screen sel ected against full-length clones, as previous reports have shown that the carboxyl terminus of Smad proteins has autoinhibitory activities (Hata et al. 1997). Indeed, we fail ed to isolate any M edea clones from two other GAL4 fusion CDNA libraries, which had not been subjected to a Notl digestion during their construction. CDNAs encoding full-length Medea polypeptides were subsequently isol ated and sequenced (see $M$ aterials and M ethods).

Figure 3 shows the conceptual protein sequence of Medea and its alignment with other members of the Smad family. The highest degree of sequencesimilarities is found in amino-terminal regions, termed $\mathrm{MH} 1$ domain (residues 36-188), and carboxy-terminal regions ( $\mathrm{MH} 2$ domain; residues 543-767). The linker region between the $\mathrm{MH} 1$ and $\mathrm{MH} 2$ domains is much less conserved and significantly longer in Medea as compared to other
Figure 3. Deduced protein sequence of Medea and sequence al ignment with other Smad proteins. Residues shared between $M$ edea and at least one other protein shown are in reverse type. Residues encoded by the alternative exon of the Medea class $A$ cDN As are shown in solid boxes. GenBank accession nos. for M edea are AF019753 and AF019754.

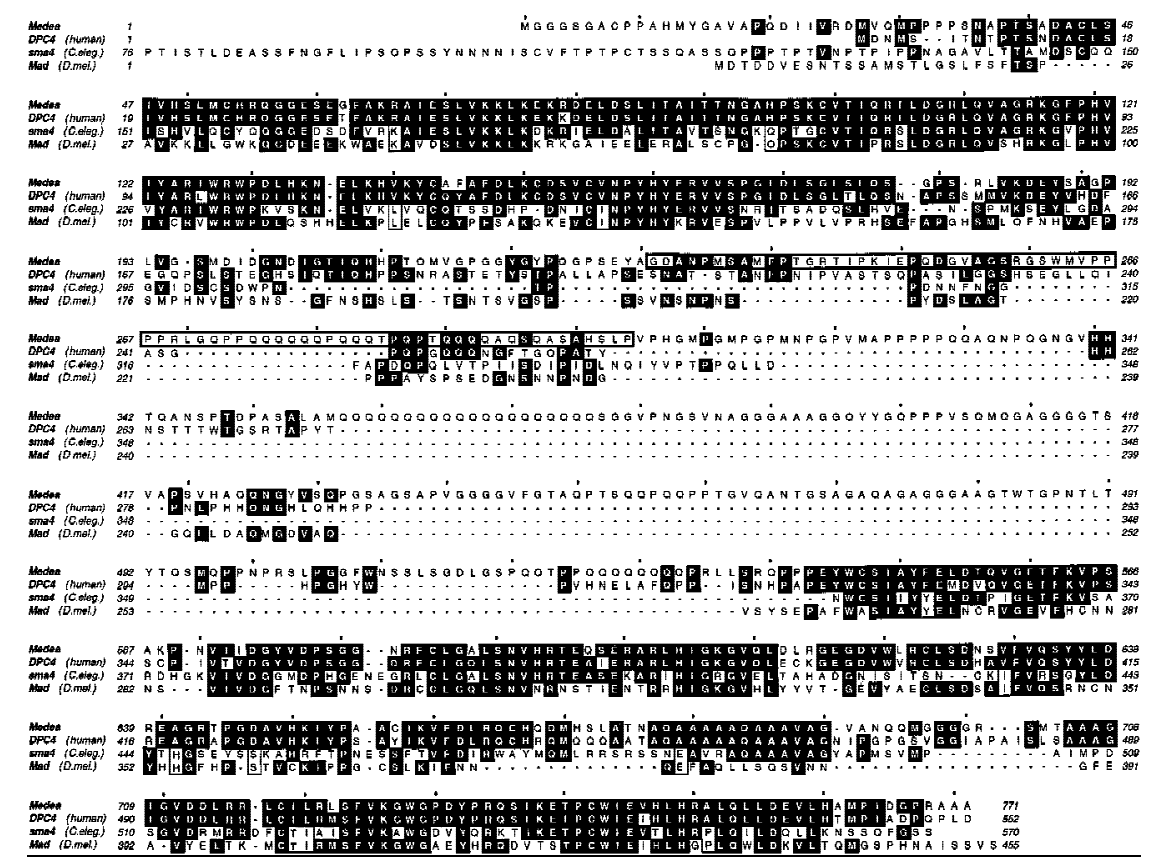


known members of the Smad family. Restriction analysis and sequence comparisons between different Medea CDNAs and genomic sequences revealed two types of CDNAs, which differ in the presence of the fourth exon. Medea type A CDNAs (which include the CDNAs obtained in theyeast screen), but not Medea type B CDNAs, contain this exon, which adds 73 amino acids to the linker region. The alternative exon (boxed in Fig. 3) contains a GIn-rich sequence, as does the portion of the linker region that is shared between the two isoforms. Sequence comparisons show that Medea bel ongs to the Smad4 subgroup of Smad proteins, as its sequence is most closely related to that of the vertebrate DPC4/ Smad4 and the Caenorhabditis elegans Sma4 proteins. Moreover, Medea lacks the carboxy-terminal sequence SSXS that is present in Mad and other members of its subgroup and is implicated in receptor-mediated serine phosphorylation (Fig. 3; M acias-Silva et al. 1996; Kretzschmar et al. 1997).

To locate the DN A-binding domain in the M edea protein, we generated a series of carboxy-terminal truncation and in-frame fusion constructs of Medea CDNAs with GAL4 AD coding sequences and tested their binding activities in the yeast system, using (D3) $5_{5} /$ lacZ as a reporter gene. As shown in Figure 4, the activity of Medea products increases upon removal of the $\mathrm{MH} 2$ domain in this assay, indicating that the $\mathrm{MH} 2$ domain of Smad4 group proteins has an inhibitory effect on DNA binding, similar to the $\mathrm{MH} 2$ domain of $\mathrm{Mad}$ group proteins (Kim et al. 1997). The presence or absence of the alternative exon 4 and of most of the linker region does not affect $M$ edea binding activity. However, by removing 10 carboxy-terminal amino acids from the $\mathrm{MH} 1$ domain, the activity drops to background levels. The linker and $\mathrm{MH} 2$ domains do not display any binding activities in this assay. Thus, it appears that the $\mathrm{MH} 1$ domain serves as the DNA-binding domain for Medea, as it does for Mad (Kim et al. 1997).

DN ase I footprinting assays with bacterial ly expressed GST fusion proteins were used to characterize the binding of Tinman and M edea to sequences of the tin-D element and to test whether $M$ ad is also able to bind. As shown in Figure 5, Tinman specifically protects the two D1 sequences that contain NK homeodomain binding sites and are required for autoregulation. The $\mathrm{MH} 1$ domains of Medea (with or without linker) protect three distinct sequences within tin-D. Importantly, one of them (nucl eotide 95-127) overlaps with the D 3 sequence that is essential and sufficient for tin-D activity and was used for the isolation of M edea. Another footprint, encompassing nucl eotide 40-68, is located in a region that has not been tested functionally, whereas the sequences included in the third protected area (nucleotide 165-190) appear not to be essential (see below; Fig. 7A). These same three regions are also protected by $\mathrm{Mad}$ ( $\mathrm{MH} 1+$ linker). However, Mad shows binding to several additional sequences, including one between nucl eotide 267 and 284 and two others between nucleotide 321 and the $3^{\prime}$ end of tin-D. Although the former site is located in the nonessential D5 region, the latter binding sites en- compass most of the $\mathrm{D} 6$ region that was shown to have a significant contribution to tin-D activity. Two other sites that are protected by $\mathrm{M}$ ad, but not $\mathrm{M}$ edea under the same conditions, correspond to the $3^{\prime}$ portion of D3 and adjacent sequences (Fig. 5A). Therefore, Mad protects most of the sequence stretch between nucl eotides 95 and 160 , which has D3 at its core, whereas Medea protects only the $5^{\prime}$ two-thirds of D3. To compare the binding specificities of $M$ ad and $M$ edea, we tested whether binding of $\mathrm{Mad}$ at lower concentrations would generate a protection pattern similar to the one observed for M edea. The results in Figure 5A (middle) show that this is not the case, as at lower concentrations, protection by Mad becomes uniformly weaker and the protection pattern typical for Medea is not observed. Taken together, the DN ase I protection data reveal a minimum of eight in vitro binding sites for M edea and Mad in the tin-D element, at least four of which are located in the essential elements D3 and D6. Moreover, it appears that Medea and $M$ ad have overlapping, but not identical, binding specificities to tin-D sequences.

Gel retardation assays provided additional information on the DN A-binding specificities of M edea and M ad and their binding sites in the tin-D element. As shown in Figure 5B, both Medea MHI (lanes 1-3) and M ad M HI (lanes 14-16) bind to ${ }^{32} \mathrm{P}$-label ed D 3 probes, and excess of

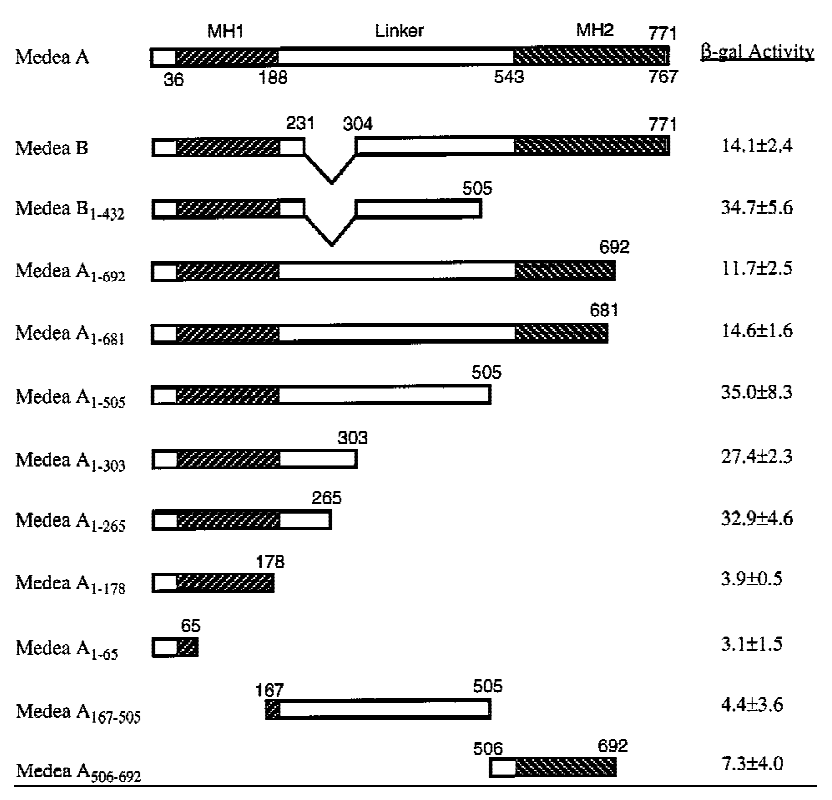

Figure 4. Activities of full length and truncated version of Medea in yeast one-hybrid assays with (tin-D3) 5 /lacZ as a reporter. The amino-terminal GAL4 AD moieties are not shown. The second and third constructs from the top represent $M$ edea class B protein derivatives that lack the portion of the linker encoded by the al ternative exon, but the numbering refers to the corresponding numbers of residues in Medea A proteins. The actual lengths of $M$ edea $B$ derivatives are provided in the names at left. $\mathrm{N}$ ote that sequences between amino acids 505 and 681 exhibit inhibitory effects on DNA binding in this assay. A truncated derivative containing residues 1-265 is still fully active, but further truncation until residue 178 abolishes activity. 
Xu et al.
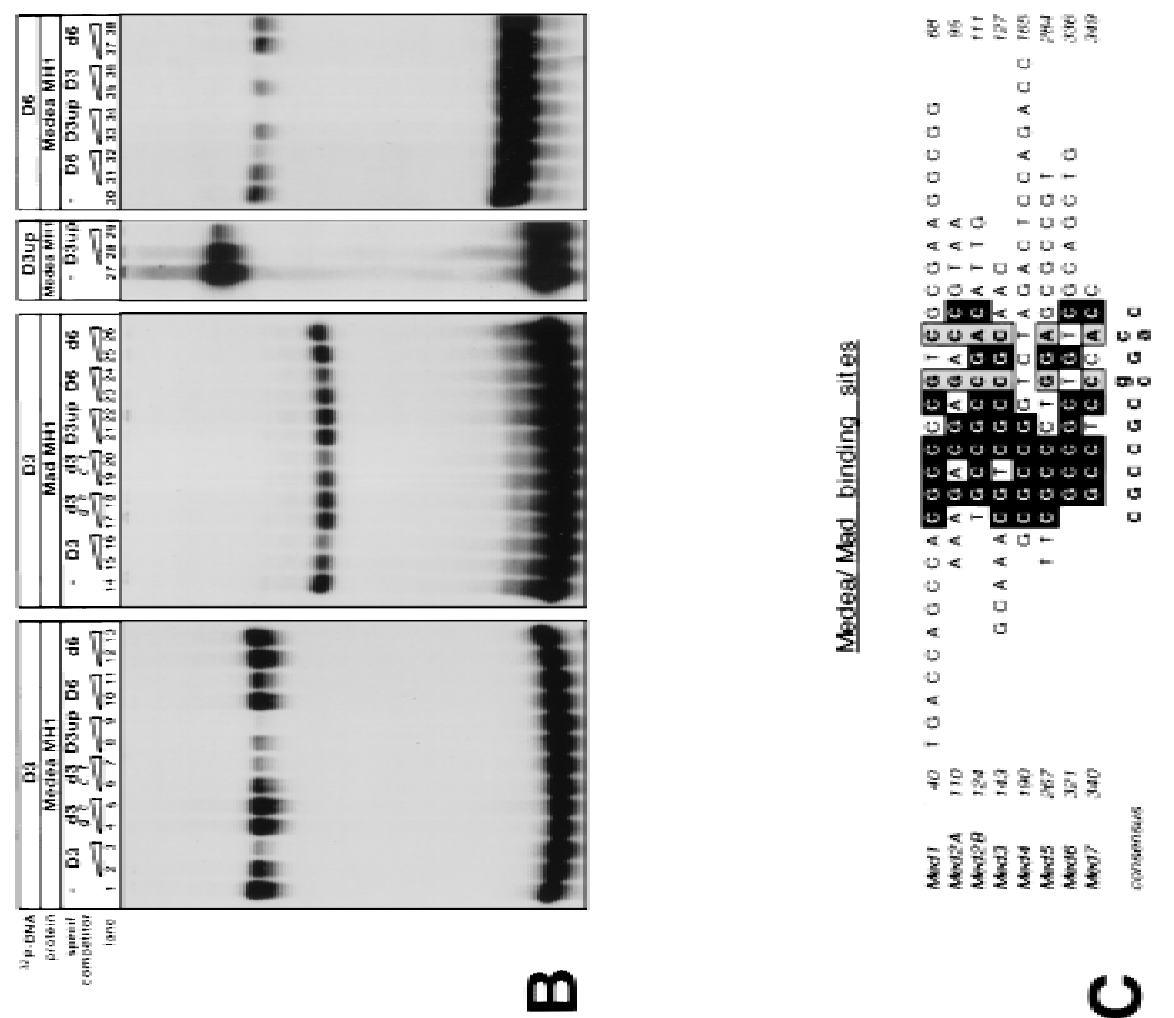

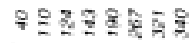

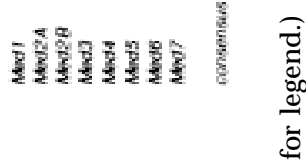

13

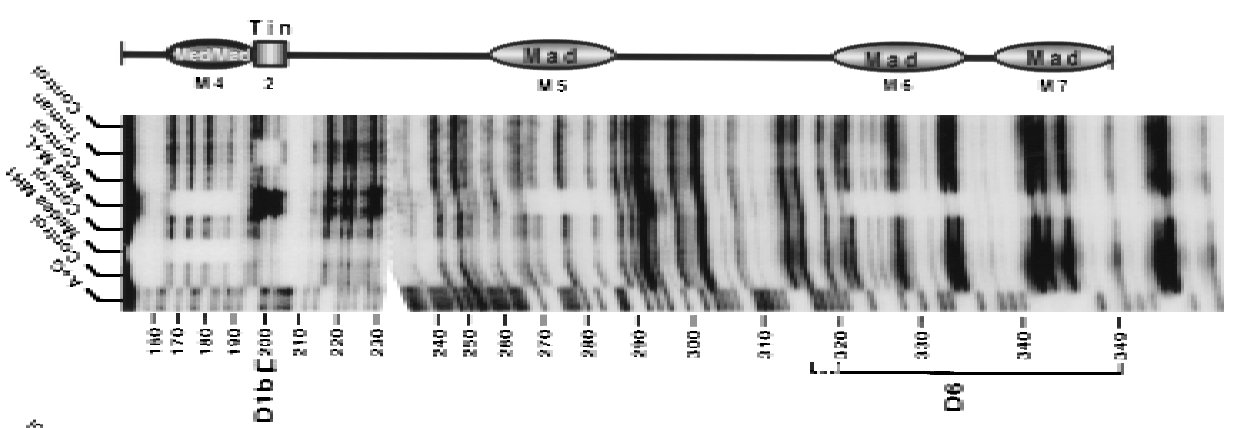

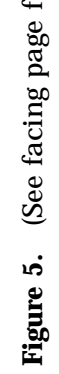
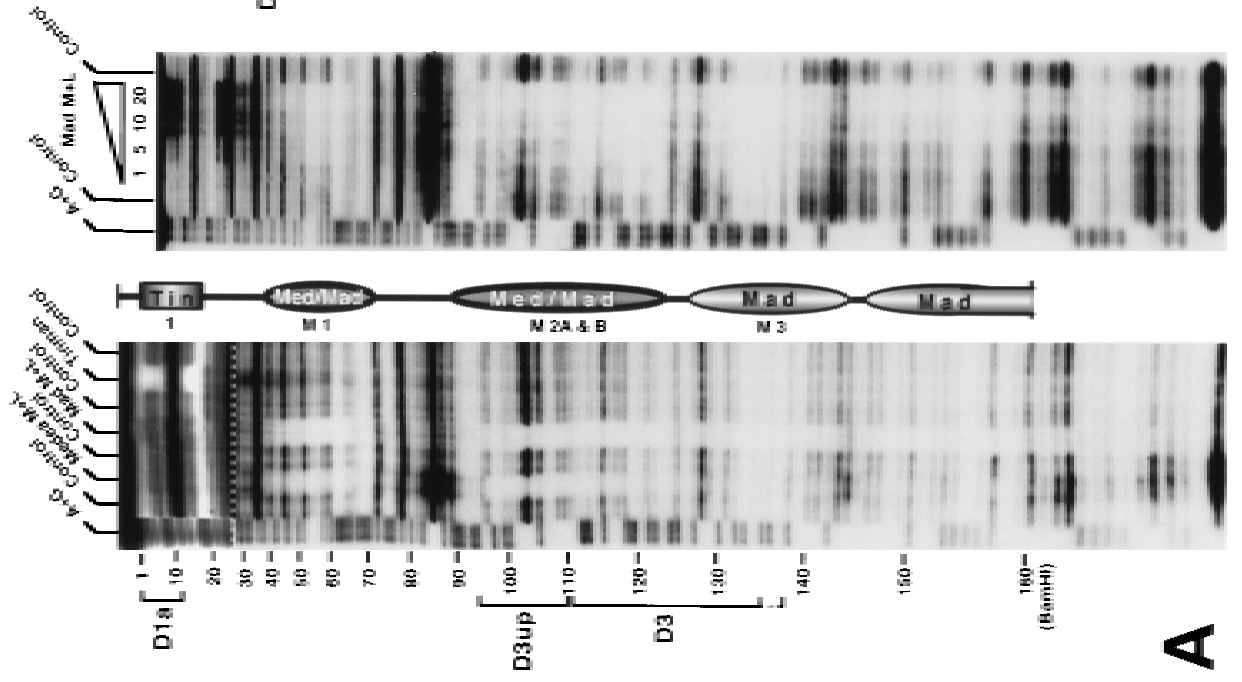
unlabel ed D3 DN A can compete for binding. Because D3 contains tandemly repeated CAATGT and GC-rich motifs, we tested which of these two sequence motifs are involved in $M$ edea and $M$ ad binding. As shown in Figure $5 B$, lanes 4 and 5 and 17 and 18, repl acement of four GCs in each of the GC-rich motifs by A's and T's renders the mutated D3 sequence unable to compete for $M$ edea and $M$ ad binding to the wild-type D 3 sequence. In contrast, in vitro mutagenesis of the CAATGT motifs (see Materials and Methods) does not interfere with Medea and $M$ ad binding, as these mutated versi ons compete equally well as D3 wild-type DN A (Fig. 5B, Ianes 6 and 7 and 19 and 20). These data show that the GC-rich motifs are essential for $M$ ad and $M$ edea binding and likely represent two distinct binding sites for these proteins in the D3 element. Because the DN ase I footprints with M edea and $M$ ad include sequences immediately upstream of D3 (Fig. 5A), we tested in gel retardation assays whether the region between nucleotide 95 and 110 (D3up) contains an additional binding site. As shown in Figure 5B, D3up is

able to specifically bind Medea (lanes 27-29) and can compete for Medea binding to D3 (lanes 8,9; note that $\mathrm{M}$ ad binding is not efficiently competed; see lanes 21,22 ). The core of D3up also contains GC-rich sequences, although in this case they are interrupted by several T's (see Fig. 1G; nucleotide 95-110). A nal ogous experiments show that the D6 region contains two GCrich stretches that are required for $M$ edea and $M$ ad binding (lanes 30-32,37,38,10-13,23-26). In agreement with the DN ase I footprinting data, M edea has a significantly weaker binding affinity to D6 as compared to D3 and D3up (lanes 30-36,10,11).

In summary, these in vitro DNA binding studies demonstrate that the functional ly significant D3 and D6 elements contain at least four GC-rich binding sites for M edea and $\mathrm{Mad}$, al though M edea binds only to those in D3 with high affinity. In addition, tin-D contains at least four other binding sites for $M$ edea and $M$ ad, all of which include GC-rich stretches. Figure 5C shows an alignment of these sequences and a consensus sequence derived from them.

Medea/Mad binding sites in D3 and D6 are required for induction by Dpp

We took advantage of the biochemical information de- scribed above to test whether in vitro binding sites of $M$ edea and $M$ ad are essential for the activity of tin-D in vivo. In these experiments, combinations of single copies of the wild-type and mutated sequences of D 3 and D 6 similar to the ones used for the in vitro binding assays were tested for their ability to activate reporter gene expression in transgenic embryos. The activity of these sequences was tested in the context of a shortened version of tin-D (tin-D*; nucleotide 1-143 plus Tin binding site 2 and nucl eotide 321-349; summarized in Fig. 6; see M aterials and M ethods). As shown in Figure 7A, tin-D* containing wild-type D 3 and D6 sequences produces an almost normal pattern of dorsal mesodermal expression, although expression levels are lower than with the complete tin-D el ement (cf. Fig. 1B). In contrast, a version in which both Medea/Mad binding sites in D3 are disrupted by 8 bp exchanges is almost completely inactive in vivo (Fig. 7B; see Fig. 5B, lanes 4,5). Similarly, expression is nearly abolished upon disruption of the two M ad binding sites in D6 or of all four M edea/Mad binding sites in D3 and D6 (data not shown; see Fig. 5B, lanes $25,26,37,38)$. Interestingly, specific disruption of the CAATGT sequences in D3 also results in a complete loss of activity in the dorsal mesoderm (Fig. 7C). Together, these data demonstrate that each of the pairs of Medea/ M ad binding sites in D 3 and D6 plays a critical role in the Dpp-induced activity of tin-D in the dorsal mesoderm. M oreover, the CAATGT sequences in D3 appear to be required for the binding of a different factor that is al so essential during this process.

An interesting difference between tin-D and tin-D* is an ectopic expression in the amnioserosa, which is observed between stage 8 and 11 of embryogenesis (Fig. 7A; data not shown). This observation suggests that the region between D3 and D6, which is missing in tin-D*, contains a repressor element for this tissue. The results with mutated versions of tin-D* indicate that the $M$ edea/ $M$ ad binding sites in D 3 and $D 6$ are necessary for amnioserosa expression (Fig. 7B), whereas the CAATGT sequences are not required (Fig. 7C; data not shown).

\section{Medea is directly required for induction of tinman and tin-D by Dpp}

To confirm that Medea is required in vivo to mediate induction of tinman and tin-D in the dorsal mesoderm,

Figure 5. In vitro DN A-binding assays with tin-D sequences. (A) DN ase I footprinting analysis with Medea, Mad, and Tinman proteins on ${ }^{32} \mathrm{P}$-labeled tin-D sequences (D. melanogaster). Forty microliters ( $1 \mu \mathrm{g}$ of Tinman and M edea and $\sim 2 \mu \mathrm{g}$ for M ad) of GST fusion proteins or GST control proteins were used per reaction, unless otherwise noted. For the high range of probe lengths, data from a longer el ectrophoretic run are shown to increase resolution (above dashed lines). N umbers correspond to those in Fig. 1G. Brackets to the left of the footprints indicate functionally important sequence stretches (see Results, Discussion, and $M$ aterials and $M$ ethods). (B) Gel mobility shift analysis with M edea and M ad GST fusion proteins ( $5 \mathrm{ng} /$ reaction) and ${ }^{32} \mathrm{P}$-label ed oligonucl eotides as indicated (cf. Fig. 1G). U nlabel ed competitor nucl eotides were added at 10xand $100 \times$ molar excess (for M edea) and at $100 \times$ and $300 \times$ molar excess (for $\mathrm{M} \mathrm{ad}$ ), respectively, as indicated by the wedges. d3 g..c and d6 are oligonucleotides mutated in the GC-rich sequences of D3 and D6, respectively, and d3 c..t is a D3 version mutated in the CAATGT sequences (see $M$ aterials and $M$ ethods). $N$ ote that $M$ ad binding is less efficiently competed by specific competitor sequences than $M$ edea, indicating a lower specific affinity of $M$ ad to target sequences as compared to M edea. (C) Sequence al ignment of M edea- and M ad-binding sequences as determined by DN ase I footprint and mobility shift assays. 
Figure 6. Schematic summary of tin-D derivatives tested for in vivo activity in transgenic embryos. Squares and ovals symbolize sequences that were protected by Tinman (tin1 and tin2) and M edea/Mad (M 1M 7) proteins, as shown in Fig. 5. Triangles symbolize CAATGT sequences. Solid symbols denote wild-type sequences; open symbols mutated sequences. (d.ms) Dorsal mesoderm; (d.ec) dorsal ectoderm; (as) amnioserosa; (n.s.) not shown.

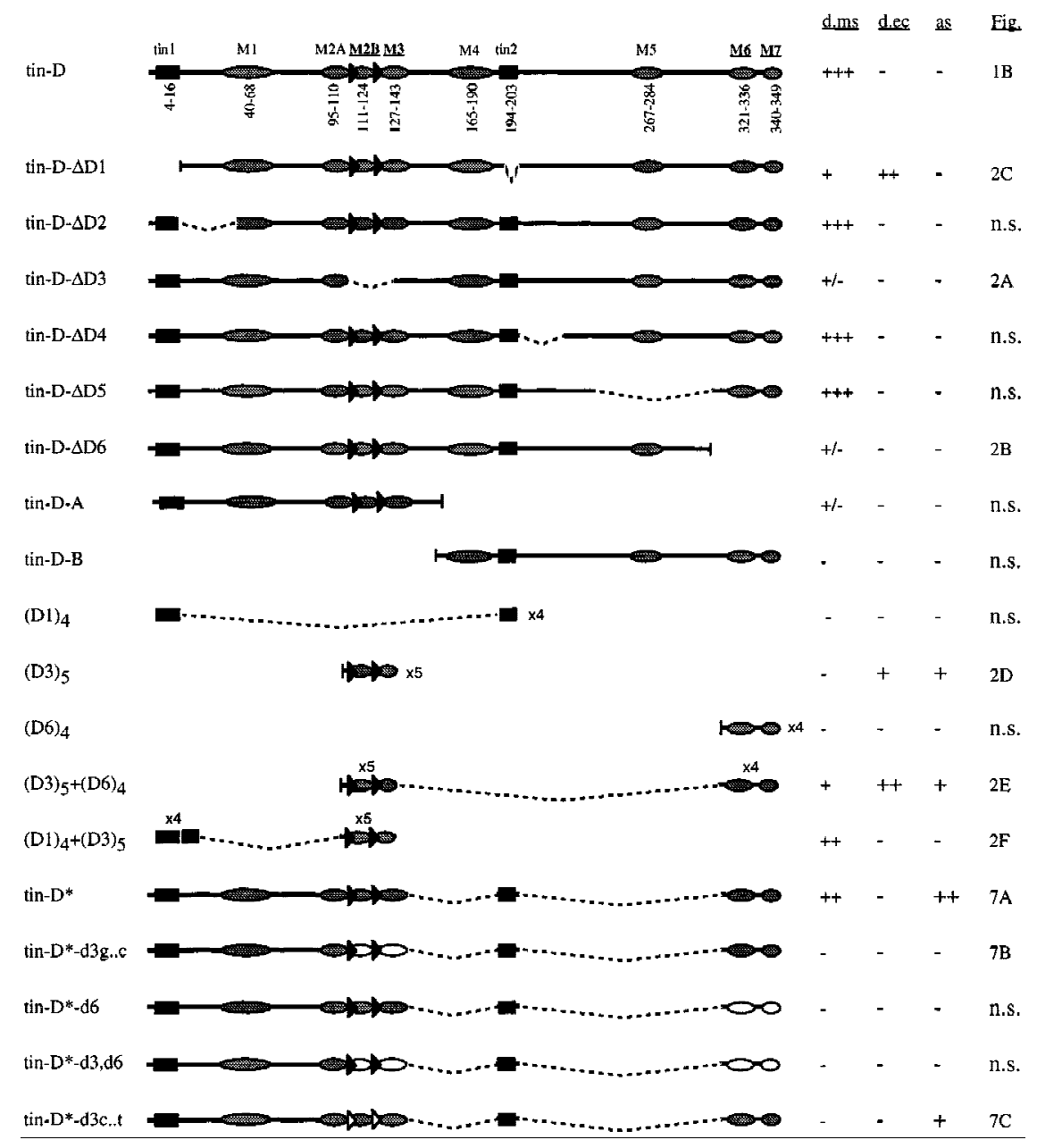

we tested its function genetically. In embryos with a reduced maternal and no zygotic activity of Medea (from homozygous $\mathrm{Med}^{15}$ females crossed with $\mathrm{Med}^{14}$ males; Hudson et al. 1998) we observe a strong reduction of dorsal mesodermal tinman expression (Fig. 7E; cf. with wild-type expression in Fig. 7G). To further test whether a complete loss of Medea activity could abolish tin-D activity, tin-D/lacZ reporter expression was examined in embryos derived from a cross between females producing homozygous $\mathrm{Med}^{13}$ germ-line clones (Hudson et al. 1998) and tin-D-lacZ/Y; Med ${ }^{14} / T M 3$, fushi tarazu ( $\mathrm{ftz}$-lacZ males. Sequence analysis of the $\mathrm{Med}^{13}$ allele showed it to be a null, as there is a $\mathrm{C} \rightarrow \mathrm{T}$ transition at position 814 of our CDN As (no. 29 and no. 0513), which causes a stop after amino acid $65(\mathrm{~K})$ of the protein (corresponding to position 39 of the ORF in Hudson et al. 1998). As shown in Figure 7, D and F, tin-D activity is virtually extinguished in germ-line clone-derived embryos that receive a paternal Medea null allele (Medea glc-null embryos), thus demonstrating that Medea is essential for tin-D induction (cf. with expression in a wildtype background, Fig. 7H). In contrast to embryos carrying a paternal $\mathrm{Med}^{14}$ allele, those carrying a wild-type copy of Medea on the paternal TM3 balancer chromo- some have significant levels of tin-D/lacZ expression in the dorsal mesoderm, showing that zygotic expression of Medea can partially compensate for the absence of maternal Medea activity (data not shown). The absence of tin-D activity in Medea glc-null embryos indicates that Medea is required in mesodermal cells downstream of the $\mathrm{Dpp}$ receptor for tinman activation. However, an alternative explanation could be that the ventral ization of the ectoderm in these embryos causes a reduction of the domains of late Dpp expression, which may indirectly prevent signaling to the mesoderm. To distinguish between a direct and an indirect requirement for Medea in tin-D activation, we injected mRN A encoding constitutively active Tkv into the ventral side of Medea glc-null embryos. As shown in Fig. 7l, embryos that expressed activated receptors $\left(T \mathrm{kv}^{\mathrm{Q}-\mathrm{D}}\right)$ in the mesoderm but lacked Medea activity were still incapable of inducing tin-D activity. In contrast, identical ly treated control embryos that were wild type for Medea showed ventrally expanded activities of tin-D, as was expected from previous experiments with ectopic Tkv ${ }^{Q-D}$ expression. (Fig. 7J, cf. with Fig. 1D). In agreement with the molecular data described above, these results demonstrate that M edea is directly required downstream of the activated Dpp re- 


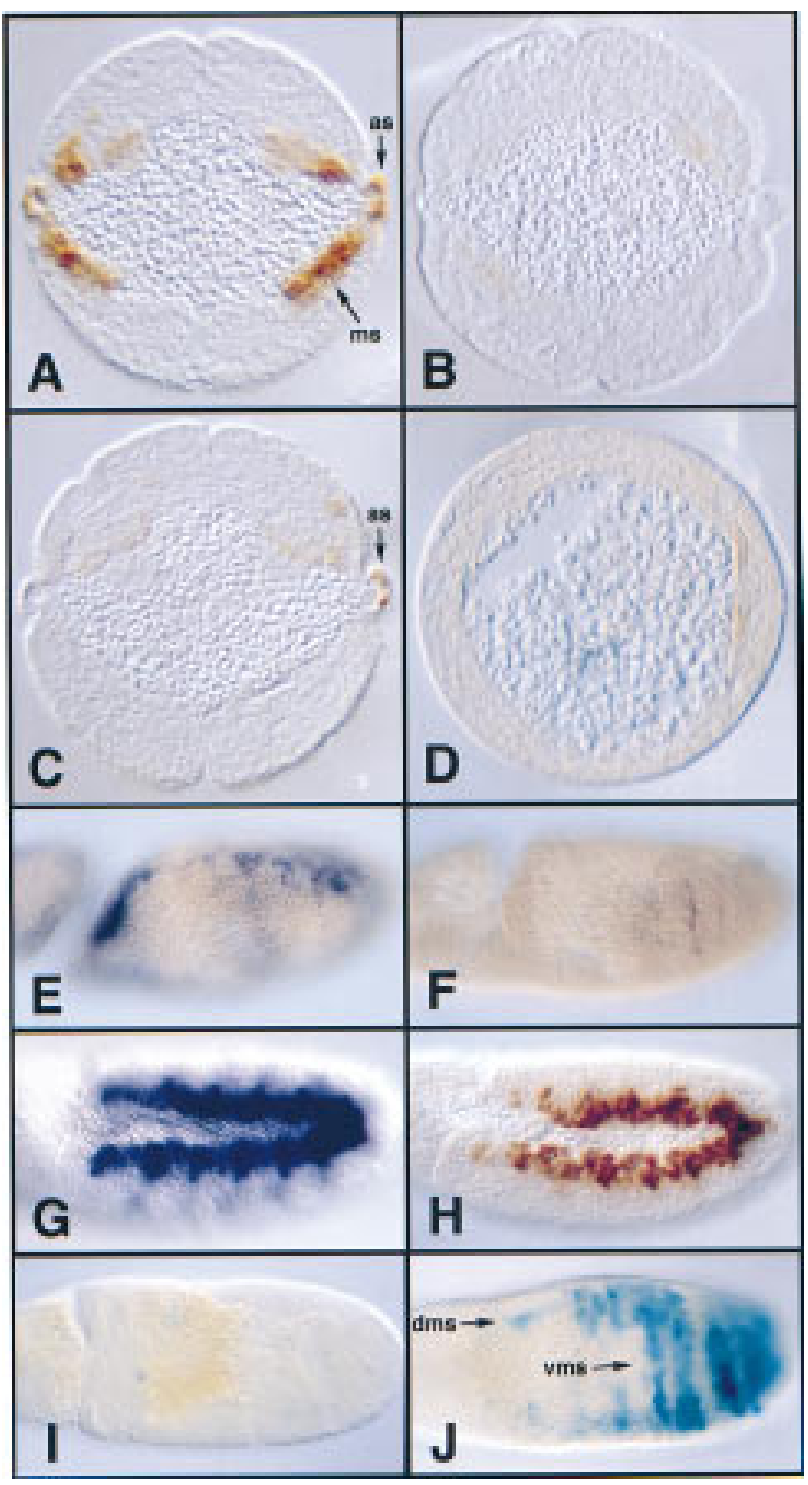

ceptor to transmit the signals to the Dpp response element of the tinman gene in the mesoderm.

\section{Discussion}

The tinman gene as a direct target of Dpp-activated Smad proteins

The data presented herein provide conclusive evidence that transcriptional activation of tinman in the cells of the dorsal mesoderm is directly controlled by a Dppdependent signaling cascade. This activation critically involves binding of D pp-activated Smad proteins to enhancer sequences located downstream of the tinman gene.

Previous studies in several different biol ogical systems have provided a reasonably clear picture of the molecular events leading to the cytoplasmic activation of Smad
Figure 7. In vivo activities of tin-D* and tin-D* versions carrying site-specific nucleotide exchanges and of tin-D in Medea germ-line clone embryos. (A) tin-D* drives largely normal expression in the dorsal mesoderm and ectopic expression in the amnioserosa of stage 11 embryos. (B) tin-D*-d3g..c is unable to respond to Dpp. (C) tin-D*-D3c..t is unable to respond to Dpp in the dorsal mesoderm. Activity in the amnioserosa indicates that in contrast to the mesoderm and ectoderm, the CAATGT sequences are not required for tin-D* induction in this tissue. Because of the thin diameters of the amnioserosa cells, $\beta$-gal staining is only seen when nuclei are hit by the sections. (D) Medea germ-line clone embryo of genotype tin-D; $\mathrm{Med}^{13} / \mathrm{Med}^{14}$ carrying tin-D/lacZ (stage 11). Only a few cells in the dorsolateral mesoderm express $\beta$-gal. (E) Med ${ }^{14}$ or $\mathrm{Med}^{15} / \mathrm{Med}^{14}$ embryo derived from $\mathrm{Med}^{15} / \mathrm{Med}^{14}$ female. tinman mRNA expression in the dorsal mesoderm is significantly reduced. (F) Same embryo as in $D$, showing only traces of residual tin-D/lacZ activity in the dorsolateral mesoderm of germ-line clone-derived Medea mutants. (G) Wild-type embryo (stage 11) stained for tinman mRN A in the dorsal mesoderm. $(\mathrm{H})$ Wild-type expression pattern of tin-D/lacZ at stage 11. (I) Medea germ-line clone embryo (stage 11) with genotype as in $D$ that was injected ventral ly with tkv ${ }^{\mathrm{Q}-\mathrm{D}}$ mRNA and stained for $\beta$-gal activity. No induction of tin-D activity is observed. () Stage 11 embryo, wild type for Medea, that was injected and stained as in I (ventral view). Ectopic tin-D induction in the ventral mesoderm is observed near the site of injection. (dms) Dorsal mesoderm; (vms) ventral mesoderm.

proteins by activated type I receptors of the BM P/TGF- $\beta$ superfamily (for review, see Hel din et al. 1997). According to this view, Smad proteins remain inactive in the cytoplasm in the absence of signaling because of inhibitory interactions between their $\mathrm{M} \mathrm{H} 1$ and $\mathrm{M} \mathrm{H} 2$ domains. Receptor activation is thought to release this block by phosphorylating residues at the carboxyl terminus (SSXS) that are present in the receptor-regulated group of Smad proteins, of which Drosophila Mad is the prototype. U pon phosphorylation, these activated Smads appear to associate with related proteins of the Smad4/ DPC4 group, which lack the corresponding phosphorylation sites. This triggers the translocation of the heteromeric Smad complex to the nucleus and ultimately leads to the transcriptional activation of target genes. In contrast to the cytoplasmic events of signal relays, the molecular events that trigger gene activation in the nucleus are still under debate. The $\mathrm{MH} 2$ domain 
of Smad4 has properties of a transcriptional activation domain, but there are differing vi ews of how Smad complexes might be tethered to promoters of target genes. A preval ent view holds that Smad complexes engage in protein-protein interactions with specific DNA-binding proteins that mediate their indirect association with promoter sequences. This proposition is largely based on the findings of Chen et al. (1996, 1997), who have demonstrated that Xenopus Smad2/Smad4 form a complex with FAST-1, a forkhead-domain protein that binds to specific target sites within an activin response element of the Mix.2 homeobox gene. However, two recent reports have shown that Smad proteins are also able to bind directly to DN A sequences. Although the Smad4binding sites in a synthetic TGF- $\beta$-inducible promoter element appear not to be essential for promoter activity (Yingling et al. 1997), a M ad-binding site in an enhancer element of vestigial, which is induced by Dpp in Drosophila wing discs, was shown to be crucial for full induction levels (Kim et al . 1997). Our present results with the Dpp response element from tinman strongly suggest that direct binding of Smad proteins to enhancer sequences could be a widespread feature of TGF- $\beta$ signal transduction and that Smad target sites play essential roles in activating the response. Although it is possible that some TGF- $\beta / B M P / D p p$ responses may rely solely on protein/protein interactions between Smads and specific DNA-binding partners, a re-examination of known or presumed response elements may identify functional Smad binding sites near the binding sites of other factors.

We have identified at least eight in vitro binding sites for Smad proteins in the tinman Dpp response el ement. Although we do not know whether all of them are occupied in vivo, we have demonstrated that four of them (two in D3 and two in D6) are indispensable for normal induction. The low residual activities in the absence of either of these two pairs may be due to partial redundancy among the binding sites within this enhancer. N everthel ess, our data clearly indicate that some binding sites have more potent functions than others, as we can, for example, delete the binding site in the D5 sequence without any noticeable effects on enhancer activity. We suggest that these differential activities of individual Smad binding sites depend on their context (see below) and/ or the specific geometry of the protein/DN A complex. Based on structural and biochemical analysis, it has been proposed that activated Smad protein complexes consist of a heterohexamer formed by the association of a Smad4 trimer with a trimer of kinase-activated Smads (Shi et al. 1997). The stoichiometry of the activated Smad complex in the nucleus is not known, but the presence of eight binding sites in the Dpp response element would in theory allow all six DN A-binding domains of a Medea/M ad heterohexamer to engage in DNA contacts.

There are several indications that $M$ ad is the endogenous partner of Medea in tinman induction: (1) It is expressed in the early mesoderm (Z. Y in and M. Frasch, unpubl.); (2) it is the only known Drosophila Smad that has the signature sequences of a BM $\mathrm{P}$ receptor-activated
Smad in its M H2 domain (Lo et al . 1998); and (3) tinman induction is mediated by $T \mathrm{kv}$, a receptor related to the BM $P$ receptor family (Brummel et al. 1994; N ellen et al. 1994; Penton et al. 1994; Y in and Frasch 1998). Our results show that the $\mathrm{MH} 1$ domains of $\mathrm{M}$ edea and $\mathrm{M}$ ad are sufficient to confer DN A binding (Figs. 4 and 5; see al so Kim et al . 1997), whereas the $\mathrm{MH} 2$ domains are required for heteromer formation (S. Zaffran, X. Xu, Z. Yin, and $M$. Frasch, in prep.). We further show that Medea and $M$ ad have different but overlapping binding specificities, as only four of the eight sites are high affinity binding sites for Medea, whereas all eight sites bind $M$ ad with comparable affinities. Because of the small number and degeneracy of presently known binding sites the molecular rules for these differences in affinities cannot be deduced. Nevertheless, our observations are compatible with a model of Medea/Mad binding as a heteromeric complex, with Medea binding to its high affinity binding sites and $\mathrm{M}$ ad to some of the remaining sequences.

Synergistic and antagonistic controls in mesoderm-specific gene activation by dpp

Although Medea/Mad binding sites are essential, they are clearly not sufficient for induction by dpp. For example, multimers of the D6 sequence that contain six bindingsites and several derivatives of the tin-D element with up to six intact binding sites lack the ability to respond to $\mathrm{Dpp}$. A major coactivator that is required for normal response to Dpp in the mesoderm is Tinman itself, which has two binding sites that are located on either side of several M edea/M ad sites. Our data show that tinman autoregulation by itself is also not sufficient for activation. Rather, Tinman and activated Medea/Mad are required in combination and therefore appear to act synergistically to trigger full levels of mesodermal tinman induction. Thus, the requirement for synergistic autoregulation by tinman, which is activated earlier by twist in a broad mesoderm-specific pattern, is one of the mechanisms to restrict tinman induction by $D p p$ to the mesodermal germ layer. This type of regulation is likely to be a common mechanism in targeting inductive responses to specific tissues. Another process in which it appears to be utilized is during Drosophila endoderm induction, where labial is originally expressed at low levels throughout the posterior midgut primordia and subsequently becomes restricted to a small domain in central regions with high expression levels. It has been shown that this restriction invol ves synergistic effects of labial autoregulation (together with exd) and dpp induction from the adjacent visceral mesoderm (Tremml and Bienz 1992; Grieder et al . 1997). Moreover, related combinatorial mechanisms could be utilized during the activation of downstream targets of certain homeobox genes. In general terms, this could explain how specific inductive responses are contingent on the particular developmental history of responding tissues. A specific example in our system may be bagpipe, which is known to requi re both tinman and dpp for its activation in clusters of dorsal mesodermal cells (Azpiazu and Frasch 1993; 
Staehling-Hampton et al. 1994; Frasch 1995). We are currently testing whether a bagpipe enhancer mimicking this pattern of expression contains functional Tinman and Smad binding sites.

The absolute requirement for the tandemly repeated CAATGT sequences for the activity of the Dpp response element strongly points to the existence of a second essential coactivator that binds to these sequences. Our results with wild-type and mutated versions of the tin-D element predict that this factor is expressed and active in both mesoderm and ectoderm, as disruption of the CAATGT motifs abolishes both mesodermal and ectopic ectodermal induction (see Fig. 6). The cl ose juxtaposition of these motifs with Smad binding sites in the minimal Dpp response element may suggest that the unknown binding factor al so participates in protein-protein interactions with bound Smad proteins. It is interesting to note that this sequence motif is closely related to that of the binding site of Xenopus FAST-1. The forkhead domain protein FAST-1 has been shown to bind to the sequences AAATGT within an activin-response element of the Mix.2 gene and to associate with Smad2 and Smad4 (Chen et al. 1996, 1997; Liu et al. 1997). It is thus concei vable that a related member of the forkhead domain protein family plays a similar role in the tinman Dpp response element, al beit in this case in a complex with DN A-associated Smads.

In addition to coactivation, we show that the Dpp response is also controlled by repression mechanisms. Strikingly, we find that the Tinman binding sites closely overlap with target sequences of a repressor, which apparently function to prevent induction of tinman by dpp in the dorsal ectoderm. Ectopic expression experiments with Tinman demonstrate that Tinman can compete with this repressing activity, and synergism between Tinman and dpp signaling can allow activation in the dorsal ectoderm. Based upon these observations, we propose the following model for the normal events of tinman induction in the dorsal mesoderm (see Fig. 8): In dorsal cells of the germ band (including both ectoderm and mesoderm), dpp signaling generates activated Medea/Mad complexes, which in combination with a CAATGT-binding factor would allow basal levels of induction in both germ layers. The binding of a repressor, which may also be present in both germ layers, near the Tinman binding sites abolishes induction in the ectoderm. In the mesoderm, however, Tinman binding competes with the binding of this repressor and acts synergistically with Medea/Mad and the CAATGT binding factor in the activation of its own D pp response element. Together with the limited activity range of $\mathrm{Dpp}$, these mechanisms would ensure that tinman induction is targeted to the dorsal mesoderm.

Interestingly, constructs lacking the presumed repressor binding sites described above are active in the dorsal ectoderm but not in other tissues that receive Dpp signals, including the amni oserosa, visceral mesoderm, endoderm, and imaginal discs (Fig. 2C-E; data not shown). The observed ectopi c reporter gene expression in the amnioserosa with some other deletion constructs (Figs. 6

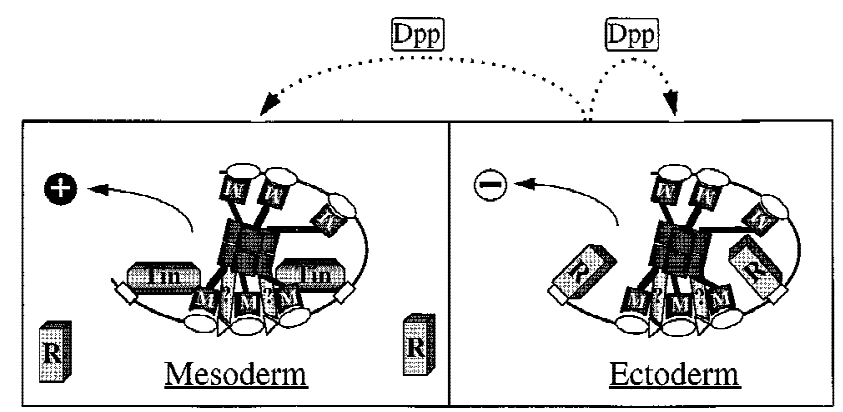

Figure 8. Model of the regulatory inputs onto the tinman Dpp response element. In the ectoderm, Dpp signaling activates Smads and triggers nuclear translocation of M edea/Mad heteromers (M). Smad complexes and a yet unknown CAATGTbinding factor (?) may be able to bind to the Dpp response element, but binding of a corepressor ( $R$ ) prevents transactivation. However, in the mesoderm, binding of Tinman protein competes with repressor binding, which leads to the formation of an active complex that triggers transactivation. Protein-protein interactions between Tinman and Smads (S. Zaffran, $X$. Xu, Z. $Y$ in, and $M$. Frasch, in prep.) could be important for the formation and activity of this complex.

and 7A,C) suggests the existence of an additional repressor, which may be dedicated to the amnioserosa. In addition, it is possible that other tissues lack the CAATGT-binding factor and perhaps utilize different coactivators such as Schnurri or CREB (Arora et al. 1995; Grieder et al. 1995; Staehling-Hampton et al . 1995; Eresh et al. 1997). Taken together, it appears that in addition to activated Smads, there is an intricate balance of differentially expressed coactivators and corepressors that bind to the tinman D pp response element and restrict its induction specifically to the dorsal mesoderm of stage 9-11 embryos.

\section{Conserved mechanisms in dorsoventral mesoderm patterning}

The signaling events in dorsoventral pattern formation have been conserved between arthropods and vertebrates to a remarkable extent, al beit with reversed polarities (Arendt and N übler-Jung 1994; Holley et al. 1995; DeRobertis and Sasai 1996). Studies in Xenopus, zebrafish, and chicken have demonstrated that dorsoventral mesoderm patterning is determined by activity gradients of bone morphogenetic proteins (BMP-2, BMP-4, and/or BM P-7), which are close homol ogs of D pp (for review, see Holley et al. 1996; Graff 1997; Thomsen 1997). Si milar to Dpp, BM Ps are involved in the induction of visceral (lateral plate) mesoderm, muscles, and the heart. Although the basic processes are strikingly similar, there are certain differences with respect to the temporal sequence and spatial rel ationships of events between flies and vertebrates. For example, although BMP expression domains include the mesoderm, and induction of ventral mesoderm in the frog embryo is initiated prior to gastrulation, dpp is produced exclusively in the ectodermal layer of early fly embryos and induces tinman only after 
the mesoderm has reached the Dpp-expressing cells as a result of gastrulation and migration processes. BMPs were shown to have graded activities in the mesoderm, which appear to be defined by antagonizing gradients of the BMP inhibitors, Chordin and Noggin (Piccolo et al. 1996; Zimmerman et al. 1996; Dosch et al. 1997; Jones and Smith 1998). Related events occur in the early embryonic ectoderm of Drosophila, where the D pp morphogen gradient is partly defined by the diffusible chordin homol og Short gastrulation (Sog; Ferguson and A nderson 1992; Biehs et al . 1996; M arques et al. 1997). With regard to the mesoderm, there appears to be a one-to-one relationship between ectodermal dpp expression domains and the tinman domains in the underlying mesoderm, which seems to obviate the need for a morphogen gradient during dorsal mesoderm induction. N onetheless, we have shown previousl y that sog prevents dorsalization of ventral mesoderm, presumably by antagonizing Dpp in the ventral ectoderm and likely in the ventral mesoderm as well (Frasch 1995). Moreover, we cannot exclude that lower activities of Dpp have yet undefined inductive functions in mesodermal areas located ventrally to the tinman domains.

The molecular mechanisms transmitting the signals into mesodermal cells through receptors and Smad proteins appear also to be conserved. Smad1 and Smad5 in synergism with Smad4 have been shown to mediate induction by BMPs in Xenopus ventral mesoderm formation (Lagna et al. 1996; Liu et al . 1996; Suzuki et al. 1997; Zhang et al. 1997). Furthermore, BM P signaling triggers the activation of certain homeobox genes in specific regions of the ventral and ventrolateral mesoderm (Ault et al. 1996; Ladher et al. 1996; Mead et al. 1996; Onichtchouk et al. 1996; Schmidt et al. 1996). Of particular interest are the findings that the tinman-related homeobox gene Nkx2.5 is induced by BMP in the precardiac mesoderm and is required for normal heart development in vertebrates (Lyons et al. 1995; Kishimoto et al. 1997; Schultheiss et al. 1997; Andrée et al . 1998). These observations suggest that the similarities between Drosophila and vertebrate genes of the tinman family extend beyond the coding regions, and that the vertebrate homologs may be driven by enhancer elements that receive synergistic inputs from Smads and other factors similar to the ones described here for Drosophila tinman.

\section{Materials and methods}

\section{Construction of P-transformation plasmids}

The construction of the reporter plasmid containing the 349-bp Dpp response element, tin-D, is described in Yin et al. (1997). Truncated versions of tin-D, tin-D-A, and tin-D-B were obtained by digestions with EcoRI-BamHI and BamHI-Xhol, respectively. Internal deletion derivatives tin-D- $\Delta D 1$ to tin-D- $\Delta D 5$ were generated from tin-D in pBluescript KS+ with the ExSite PCR-Directed Mutagenesis Kit (Stratagene) using primers that flank the deleted sequences. For tin-D- $\Delta D 1$, an intermediate with a del eted $D$ la sequence was generated from a PCR product obtained with the $5^{\prime}$ primer CAGAATTCACTAAACATGACCTAATG and a 3' M13 primer. The Dlb sequence was deleted subsequently by in vitro mutagenesis as above. U pon sequence confirmation of the del etions, the mutated fragments were cloned into the $\mathrm{N}$ otl-Xhol sites of the $\mathrm{pC}$ asperhs 43 vector.

To generate tandemly aligned multiple copies of D1, D3, and D6, the following oligonucleotide pairs were designed with asymmetric Aval sites at both ends: D1, TCGGGTGTCAAGTGGCATCTCAAGTGGAG/CACAGTTCACCGTAGAGTTCACCTCAGCC; D3, TCGGGTTTCAATGTCGGCGGCAATGTTGCGGCGACG/CAAAGTTACAGCCGCCGTTACAACGCCGCTGCAGCC; D6, TCGGGAGCCGCTGTCGCAGCTGCGAGCCTCCCAC/CTCGGCGACAGCGTCGACGCTCGGAGGGTGAGCC. The annealed oligonucleotides were ligated with an Aval-Xbal-digested 489S vector. (provided by Dr. T. Lufkin, M ount Sinai School of M edicine, $\mathrm{N}$ ew York, NY). The resulting products were treated with Klenow polymerase, blunt-end ligated, and transformed into XL-1. The copy number of positive clones was determined by sequencing. Inserts with multiple copies were excised with EcoRI-BamHI and cloned into pCasper hs43 for P-transformation. For yeast one-hybrid screenings, the same EcoRI-BamHI fragments from the $489 \mathrm{~S}$ vector were cloned into pBluescript $\mathrm{KS}+$, from which they were recloned as EcoRI-Xbal fragments into the pHisi and $\mathrm{pHISi}-1$ vectors and as EcoRI-Xhol fragments into the placZi reporter. The P-transformation constructs containing $(\mathrm{D} 1)_{4}+(\mathrm{D} 3)_{5}$ were generated by cloning an EcoRI-BamHI fragment with four copies of D1 into pCasperhs43 and sequentially adding an BamHI-Sall fragment with five copies of D3 into the BamHI-Xhol sites. The construct (D3) $5+$ (D6)4 was generated analogously by cloning an EcoRI-BamHI fragment with five copies of D3 and an BamHISall fragment with four copies of D6 into pCasper hs43. The orientations were $(\gg D 1 \gg) 4-(\gg D 3 \gg)_{5} /$ lac $Z$ and $(\gg D \text { 6 } \gg)_{4}-(\gg D \text { D } \gg)_{5} /$ lacZ (where $>$ denotes $5^{\prime} \rightarrow 3^{\prime}$, as shown in Fig. 1G).

For the series of constructs with elements carrying base pair exchanges, a PCR fragment, including the 1-113 bp of tin-D, was cloned into the EcoRI-BamHI sites of pCasperhs43. Subsequently, annealed oligonucleotides with combined Dlb sequences and D6* (wild type; nucleotide 321-349 of tin-D) or d6* (mutated in the GC stretches) sequences, respectively, were cloned into the BamHI-Xhol sites of this construct. Finally, oligonucleotides D3* (wild type; nucleotide 114-150 of tin-D), d3g...* (mutated in the GC-rich sequences), or d3c..t* (mutated in CAATGT) were cloned into the BamHI site to generate tinD*, tinD*-d3g..c, tinD*-d6, tinD*-d3c..t, and tinD*-d3-d6, respectively (see Fig. 6). The native orientations were verified by PCR. The sense strands of the oligonucleotides had the following sequences (mutated sequences are underlined): D6*, GGATCCTCAAGTGGACAAGAGCCGCTGTCGCAGCTGCGAGCCTCCCACCTCGAG;d6*, GGATCCTCAAGTGGACAAGAGTATCTATCGCAGCTGCGATATTCACACCTCGAG; D3*, GGATCCATTACGGTCTCGTCTTTCAATGTCGGCGGCAATGTTGCGGCGACGTTTGCAGATCT; d3c..t*, GGATCCATTACGGTCTCGTCTTTIACTTACCGGCGGTACT ACTGCGGCGACGTTTGCAGAT $\bar{C} T ;$ d3g... ${ }^{*}$, GGATCCATTACGGTCTCGTCTTTCAATGT $\underline{A T G C A T C A A T G T T} \underline{\text { ATGGATACGTTTGCAG- }}$ ATCT.

\section{One-hybrid screening}

The MATCHMAKER One-Hybrid System (Clontech) was used. placZi and pHISi/pHISi-1, with five copies of D3, were transformed into the yeast strain YM 4271 to be integrated into the genome. A 3-AT concentration of $10 \mathrm{~mm}$ was determined to be sufficient to suppress the basal activity of $\mathrm{His}$ and was used for 
the screen. Three Drosophila Gal 4 hybrid cDN A libraries were screened; a 0- to 16-hr embryonic library in pGAD 10 (Clontech); a 0- to 6-hr embryonic library in $\lambda A C T$ (gift from Leslie Pick, Mount Sinai Medical School, N ew York, NY); and a 3- to 12-hr embryonic library in pGADN ot (gift from Richard Mann, Columbia University, N ew York, NY). In the first step, His selection was used to identify surviving clones. Positives were further verified by lacZ activity tests and by retransformation into the YM 4271 reporter strain and retesting them for growth and lacZ activity. Fifty-four potentially interesting CDNAs that remained positive after these tests were sequenced and subjected to BLAST searches. Eight of them had identical sequences that showed high similarities to Smad4. Yeast reporter plasmids with four copies of D1 (which contains tandemly arranged Dla and Dlb sequences; see above) were generated and used in anal ogous yeast one-hybrid screens, which resulted in the isolation of two Gal4 fusion clones containing tinman CDNA sequences.

Construction of plasmids to generate derivatives of M edea, Mad, or tinman

The cDN A insert from the initially isolated GAL4 fusion clone 3.15 (pGAD-Medea $A_{1-681}$ ) was used to isolate full-length CDN A clones from a 4- to 8-hr embryonic cDN A library (Brown and Kafatos 1988). The obtained clones 14 (which, like 3.15, corresponds to the Medea A splicing product), and 29 (Medea B), were analyzed further, and the inserts of CDNAs 3.15 and 29 were sequenced in their entirety. The Xmnl-Bglll fragment from pGAD-M edea $A_{1-681}$ was cloned into BamHI(blunted)Bglll of pGAD424 vector to generate pGAD424-3.15. These clones were used to generate the following derivatives in pGAD. pGAD-Medea $A_{1-692}$ : A 1.9-kb fragment from a Notl partialPstl digestion of Medea 14 (pN B40) was cloned into Pstl-N otl of pGAD 424-3.15. pGAD-Medea $A_{1-505}$ : Pstl-Smal from Medea 14 (pN B40) into Pstl-N otl (blunted) fragment of pGAD 424-3.15. pGAD-Medea $A_{1-265}$ : Medea-3.15 (KS+) was first generated by cloning the $\mathrm{Xmnl}-\mathrm{N}$ otl insert from pGAD-Medea $A_{1-681}$ into Smal-Notl of the KS+ vector. BamHI-Kpnl (blunted) from Medea-3.15 (KS+) was then cloned into BamHI-EcoRI(blunted) of pGAD10. pGAD-Medea $A_{1-303}$, pGAD-Medea ${ }_{1-65}$ : Nested 3'-del etions were generated by DN ase I treatment of pGAD4243.15, Notl digestion, Klenow, ligation, and Sall digestion, followed by transformation and sequencing of truncated clones. pGAD-Medea $A_{167-505}$ : N ested 5'-deletions were generated by DN ase I treatment of KS-Medea-3.15 as above. One of the obtained clones, Medea $\mathrm{A}_{167-681}(\mathrm{KS}+)$, was cut with EcoRI (blunted)-Xhol, and the fragment was cloned into Bglll(blunted)-Sall of a pGAD 424 vector that had been cut with BamH1, blunted, and religated to adjust the reading frame, pGAD424. pGADMedea $A_{506-692}$ : Smal-Bglll from pGAD-Medea $A_{1-692}$ into Smal-Bglll of a pGAD424 vector that had been cut with EcoRI, blunted, and religated to adjust the reading frame. pGADMedea $\mathrm{B}_{1-432}$ : Pstl-Smal from Medea 29 (pN B40) into Pstl-N otl (blunted) of pGAD424-3.15. pGAD-Medea B: pGAD-Medea was first generated by cloning a Notl fragment from Medea 29(pN B40) into Notl of pGAD424-3.15. A Pstl fragment of Medea 29(pN B40) was then cloned into the Pstl site of pGADMedea.

For in vitro DNA-binding experiments, GST-fused Medea proteins were generated. Xmnl-EcoRI from pGAD-Medea $A_{1-}$ 681 was cloned into Smal-EcoRI of pGEX-3X to generate GSTMedea $_{\mathrm{MH} 1+\mathrm{L}}$. BamHI-Kpnl (blunted) from Medea-3.15 (KS+) was cloned into BamHI-Smal of pGEX-2T to generate GST Medea $_{\mathrm{MH} 1}$. GST-tinman was generated by cloning a BamHIEcoRV fragment from pQE-tinman (N K-4-6; Yin et al. 1997), and the EcoRV-EcoRI fragment of tinman CDNA (NK4-8 in pN B40) into BamHI-EcoRI of pGEX-3X.

A 200-bp fragment of Mad was PCR amplified from Drosophila genomic DNA using the primers CAGGATCCACACCGACAGCAGCGCGATG (which deletes 5 codons at the amino terminus) and CCAGACTGTCGACGGCCTTC. The fragment was cloned into the BamHI-Sall of KS+ and used to isolate the full-length Mad cDN As (Brown and Kafatos 1988). The BamHI-Sall digested 200-bp PCR product and the SallNotl fragment from a Mad CDNA in pN B40 were then cloned into BamHI-N otl of the KS+vector to generate Mad (KS+). Bam$\mathrm{HI}-\mathrm{Pvull}$ (blunted) from Mad (KS+) was cloned into BamHISmal of pGEX-3X to generate GST-Mad $\mathrm{MH}_{\mathrm{M}+\mathrm{L}}$. BamHI-EcoRI (blunted) of Mad (KS+) was cloned into BamHI-Smal of pGEX$3 \mathrm{X}$ to generate $\mathrm{GST}-\mathrm{Mad}_{\mathrm{MHI}}$.

Yeast assays for lacZ activities

Yeast assays were based on a protocol from Steven Hanes (SUNY, Albany). Fresh yeast cells were inoculated into $3 \mathrm{ml}$ of selective culture medium and grown at $30^{\circ} \mathrm{C}$ to saturation. These cultures were used to start new cultures at an $O D_{600}$ of 0.1 , which were grown at $30^{\circ} \mathrm{C}$ to a final $O D_{600}$ of $\sim 0.4$. After chilling on ice the $\mathrm{OD}_{600}$ was measured, $1 \mathrm{ml}$ of the cells was pelleted, and the resuspended pellets were vortexed in $200 \mu \mathrm{l}$ of $0.1 \mathrm{M}$ Tris (pH 7.5), $0.05 \%$ Triton X-100. After freezing on dry ice, cells were thawed on ice. One milliliter ONPG solution (16.1 grams/liter $\mathrm{Na}_{2} \mathrm{HPO}_{4} \cdot 7 \mathrm{H}_{2} \mathrm{O}$, 5.5grams/liter $\mathrm{N} \mathrm{aH}_{2} \mathrm{PO}_{4} \cdot \mathrm{H}_{2} \mathrm{O}, 0.75$ grams/liter $\mathrm{KCl}, 0.246$ grams/liter $\mathrm{M} \mathrm{gSO}_{4} \cdot 7 \mathrm{H}_{2} \mathrm{O}, 0.8$ grams/liter ONPG, $1.25 \mathrm{~mm}$ DTT, $0.00625 \%$ SDS, $0.27 \% \beta$-mercaptoethanol) was added, and the suspension was incubated at $30^{\circ} \mathrm{C}$. When the color reaction appeared to have reached maximum levels, reaction times (t) were recorded and $500 \mu \mathrm{l} 1 \mathrm{M} \mathrm{N} \mathrm{a}_{2} \mathrm{CO}_{3}$ were added. After centrifugation, the $\mathrm{OD}_{420}$ values were taken from the supernatants. The lacZ activities of five independent clones were measured for each construct and calculated with the formula

$$
\beta \text {-gal units }=\frac{\mathrm{OD}_{420} \times 1000}{O D_{600} \times \mathrm{t}(\mathrm{min} / \text { reaction time })}
$$

\section{DNase I footprinting and gel mobility-shift assays}

Footprinting assays were performed as described in Yin et al. (1997). For gel-shift analysis, 5 pmoles of anneal ed oligonucleotides were labeled with [ $\left.{ }^{32} \mathrm{P}\right]-\mathrm{dCTP}$ using Klenow polymerase and purified by PAGE. Binding reactions were performed in a $10-\mu$ l volume on ice with $10,000 \mathrm{cpm}$ of probes, appropriate amounts of protein, $0.5 \mathrm{\mu g}$ of nonspecific competitor poly[d(A-T)] and specific competitor DN A in 4\% Ficoll, $20 \mathrm{~mm}$ HEPES (pH 7.6), $50 \mathrm{~mm} \mathrm{KCl,} 1 \mathrm{~mm}$ EDTA, $1 \mathrm{~mm}$ DTT, and $0.25 \mathrm{mg} / \mathrm{ml} \mathrm{BSA}$. After a 30-min incubation, the mixtures were loaded on a pre-run $4 \%$ polyacrylamide/bisacrylamide gel (30:1) and run at $12 \mathrm{~V} / \mathrm{cm}$ in $0.5 \times \mathrm{TBE}$ buffer for $3 \mathrm{hr}$. The dried gels were exposed for $12 \mathrm{hr}$. The following oligonucleotides were used as labeled probes and/or as specific competitors (mutated nucleotides are underlined): D3up, GGCATTACGGTCTCGTCTTT; D3-WT, TCGGGTTTCAATGTCGGCGGCAATGTTGCGGCGACGTCGG; d3 g..C, TCGGGTTTCAATGTATGCATCAATGTTATGGATACGTCGG; d3 c..t, TCGGGTTTCGGTTTCGGCGGCG $\overline{G T}$ TTGCGGCGACGTCGG; D6-WT, GGÄTCCTCAAGTGGACAAGAGCCGCTGTCGCAGCTGCGAGCCTCCCACCTCGAG; d6, GGATCCTCAAGTGGACAAGAGTATCTATCGCAGCTGCGATATTCACACCTCGAG. 


\section{Drosophila strains and embryo stainings}

Drosophila lines with the foll lowing genotypes were used for the experiments: $\mathrm{dpp}^{\mathrm{H} 46}$ (Wharton et al. 1993); $\mathrm{P}\{$ en2.4-GAL4\}en (A. Brand, unpubl.); $\mathrm{Med}^{13}$, Med ${ }^{14}$, and $\mathrm{Med}^{15}$ (Hudson et al. 1998); $\operatorname{tin}^{346}$ (Azpiazu and Frasch 1993); UAS-tin (Yin and Frasch 1998); UAS-tkv Q253D (Nellen et al. 1996). GALSG30, which is homozygous for twi-GAL4 (on X chromosome) and 24B (Brand and Perrimon 1993; G reig and Akam 1993), was used as a mesodermal driver line. Medea germ line clones were generated as described in Hudson et al. (1998). For genetic crosses involving tin-D, the insertion tin-D7-25/lacZ (X chromosome) was used. Embryos were stained and cross sectioned as described previously (Frasch 1995; Y in et al. 1997). The expression patterns of at least three independent insertions were analyzed for each lacZ reporter construct. Homozygous mutant embryos were identified using $\beta$-gal-expressing bal ancers. In some cases, homozygous tinman mutants were identified by the absence of Even-skipped-expressing pericardial progenitors.

mRNA injections into embryos

tkv ${ }^{\mathrm{Q}-\mathrm{D}}$ mRN A was transcribed from pSP35T-tkv-a and capped in vitro as described in Hudson et al. (1998). Injections were done as described except that mRNAs were injected mid-ventrally to direct them preferentially to the mesoderm and at stage 4 , just prior to cellularization, to ensure their perdurance until stages 10-11. U pon aging to stage 11, the embryos were fixed and stained with $\mathrm{X}$-gal for $\beta$-gal activity.

\section{Acknowledgments}

We thank Leslie Pick and Richard M ann for CDN A libraries and the Akam, Basler, and Perrimon laboratories for fly stocks. We appreciate the helpful comments of Hanh N guyen and Chris Rushlow on the manuscript. This work was supported by grants from the National Institutes of Health (NIH) (HD 30832) and from the American Heart Association to M.F., and by a grant from the NIH (GM 50838) to E.L.F.; E.L.F. and M.F. were also recipients of awards from the Pew Scholars Program in the Biomedical Sciences.

The publication costs of this article were defrayed in part by payment of page charges. This article must therefore be hereby marked "advertisement" in accordance with 18 USC section 1734 solely to indicate this fact.

\section{References}

Andrée, B., D. Duprez, B. Vorbusch, H.-H. Arnold, and T. Brand. 1998. BM P-2 induces ectopic expression of cardiac lineage markers and interferes with somite formation in chicken embryos. Mech. Dev. 70: 119-131.

Arendt, D. and K. N übler-Jung. 1994. Inversion of dorsoventral axis? Nature 37: 26.

Arora, K., H. Dai, S. Kazuko, J. Jamal, M. O'Connor, A. Letsou, and R. Warrior. 1995. The Drosophila schnurri gene acts in the $\mathrm{Dpp} / \mathrm{TGF} \beta$ signaling pathway and encodes a transcription factor homologous to the human MBP family. Cell 81: 781-790.

Ault, K., M. Dirksen, and M. Jamrich. 1996. A novel homeobox gene PV.1 mediates induction of ventral mesoderm in Xenopus embryos. Proc. Natl. Acad. Sci. 93: 6415-6420.

Azpiazu, N. and M. Frasch. 1993. tinman and bagpipe: Two homeo box genes that determine cell fates in the dorsal mesoderm of Drosophila. Genes \& Dev. 7: 1325-1340.

Biehs, B., V. Francois, and E. Bier. 1996. The Drosophila short gastrulation gene prevents D pp from autoactivating and suppressing neurogenesis in the neuroectoderm. Genes \& Dev. 10: 2922-2934.

Bienz, M. 1994. Homeotic genes and positional signalling in the Drosophila viscera. Trends Genet. 10: 22-26.

Bier, E. 1997. Anti-neural-inhibition: A conserved mechanism for neural induction. Cell 89: 681-684.

Bodmer, R. 1993. The gene tinman is required for specification of the heart and visceral muscles in Drosophila. Development 118: 719-729.

Bodmer, R., L.Y. Jan, and Y.N. Jan. 1990. A new homeoboxcontaining gene, msh-2, is transiently expressed early during mesoderm formation of Drosophila. Development 110: 661669.

Brand, A.H. and N. Perrimon. 1993. Targeted gene expression as a means of altering cell fates and generating dominant phenotypes. Development 118: 401-405.

Brown, N.H. and F.C. Kafatos. 1988. Functional cDN A libraries from Drosophila embryos. J. Mol. Biol. 203: 425-437.

Brummel, T., V. Twombly, G. M arqués, J. Wrana, S. N ewfeld, L. Attisano, J. Massagué, M. O'C onnor, and W. Gelbart. 1994. Characterization and relationship of Dpp receptors encoded by the saxophone and thick veins genes in Drosophila. Cell 78: 251-261.

Chen, C. and R. Schwartz. 1995. Identification of novel DNA binding targets and regulatory domains of a murine tinman homeodomain factor, nkx-2.5. J. Biol. Chem. 270: 1562815633.

Chen, X., M. Rubock, and M. Whitman. 1996. A transcriptional partner for MAD proteins in TGF- $\beta$ signaling. Nature 383: 691-696.

Chen, X., E. Weisberg, V. Fridmacher, M. Watanabe, G. N aco, and M. Whitman. 1997. Smad4 and FAST -1 in the assembly of activin-responsive factor. N ature 389: 85-89.

Damante, G., L. Pellizzari, G. Esposito, F. Fogolari, P. Viglino, D. Fabbro, G. Tell, S. Formisano, and R. Di Lauro. 1996. A molecular code dictates sequence-specific DNA recognition by homeodomains. EMBO J. 15: 4992-5000.

Das, P., L.L. Maduzia, H. Wang, A.L. Finelli, S.-H. Cho, M.M. Smith, and R.W. Padgett. 1998. The Drosophila gene Medea demonstrates the requirement for different classes of Smads in dpp signaling. Development 125: 1519-1528.

DeRobertis, E. and Y. Sasai. 1996. A common plan for dorsoventral patterning in Bilateria. Nature 380: 37-40.

Dosch, R., V. Gawantka, H. Delius, C. Blumenstock, and C. $\mathrm{N}$ iehrs. 1997. Bmp-4 acts as a morphogen in dorsoventral patterning in Xenopus. Development 124: 2325-2334.

Eresh, S., J. Riese, D. Jackson, D. Bohmann, and M. Bienz. 1997. A CREB-binding site as a target for decapentaplegic signalling during Drosophila endoderm induction. EMBO J. 16: 2014-2022.

Ferguson, E. and K. Anderson. 1992. decapentaplegic acts as a morphogen to organize dorsal-ventral pattern in the Drosophila embryo. Cell 71: 451-461.

Frasch, M. 1995. Induction of visceral and cardiac mesoderm by ectodermal Dpp in the early Drosophila embryo. Nature 374: 464-467.

Gajewski, K., Y. Kim, Y. Lee, E. Olson, and R. Schulz. 1997. $D$-mef2 is a target for Tinman activation during Drosophila heart development. EMBO J. 16: 515-522.

Graff, J. 1997. Embryonic patterning: To BMP or not to BMP, that is the question. Cell 89: 171-174.

Greig, S. and M. Akam. 1993. Homeotic genes autonomously specify one aspect of pattern in the Drosophila mesoderm. Nature 362: 630-632.

Grieder, N., D. N ellen, R. Burke, K. Basler, and M. Affolter. 
1995. Schnurri is required for Drosophila Dpp signaling and encodes a zinc finger protein similar to the mammalian transcription factor PRDII-BF1. Cell 81: 791-800.

Grieder, N., T. Marty, H.-D. Ryoo, R. Mann, and M. Affolter. 1997. Synergistic activation of a Drosophila enhancer by HOM /EXD and DPP signaling. EMBO J. 16: 7402-7410.

Hata, A., R. Lo, D. Wotton, G. Lagna, and J. Massagué. 1997. Mutations increasing autoinhibition inactivate tumour suppressors Smad2 and Smad4. N ature 388: 82-87.

Heldin, C.-H., K. Miyazono, and P. ten Dijke. 1997. TGF- $\beta$ signalling from cell membrane to nucleus through SM AD proteins. Nature 390: 465-471.

Holley, S., P. Jackson, Y. Sasai, B. Lu, E. De Robertis, F. Hoffmann, and E. Ferguson. 1995. A conserved system for dorsalventral patterning in insects and vertebrates involving sog and chordin. Nature 376: 249-253.

Holley, S., J. N eul, L. Attisano, J. Wrana, Y. Sasai, M. O'Connor, E. De Robertis, and E. Ferguson. 1996. The Xenopus dorsalizing factor noggin ventralizes Drosophila embryos by preventing DPP from activating its receptor. Cell 86: 607-617.

Hudson, J., S. Podos, K. Keith, S. Simpson, and E. Ferguson. 1998. The Drosophila Medea gene is required downstream of $\mathrm{dpp}$ and encodes a functional homolog of human Smad4. Devel opment 125: 1407-1420.

Jones, C. and J. Smith. 1998. Establishment of a BM P-4 morphogen gradient by long-range inhibition. Dev. Biol. 194: 12-17.

Kim, J., K. Johnson, H. Chen, S. Carroll, and A. Laughon. 1997. Drosophila Mad binds to DNA and directly mediates activation of vestigial by Decapentaplegic. Nature 388: 304-308.

Kishimoto, Y., K.-H. Lee, L. Zon, M. Hammerschmidt, and S. Schulte-Merker. 1997. The molecular nature of zebrafish swirl: BMP2 function is essential during early dorsoventral patterning. Development 124: 4457-4466.

Kretzschmar, M., F. Liu, A. Hata, J. Doody, and J. Massagué. 1997. The TGF- $\beta$ family mediator Smad1 is phosphorylated directly and activated functionally by the BM $\mathrm{P}$ receptor kinase. Genes \& Dev. 11: 984-995.

Ladher, R., T. Mohun, J. Smith, and A. Snape. 1996. Xom: A Xenopus homeobox gene that mediates the early effects of BM P-4. Development 122: 2385-2394.

Lagna, G., A. Hata, A. Hemmati-Brivanlou, and J. Massagué. 1996. Partnership between DPC4 and SMAD proteins in TGF- $\beta$ signalling pathways. Nature 383: 832-836.

Liu, F., A. Hata, J. Baker, J. Doody, J. Carcamo, R. Harland, and J. Massagué. 1996. A human Mad protein acting as a BM Pregulated transcriptional activator. Nature 381: 620-623.

Liu, F., C. Pouponnot, and J. Massagué. 1997. Dual role of the Smad4/DPC4 tumor suppressor in TGF $\beta$-inducible transcriptional complexes. Genes \& Dev. 11: 3157-3167.

Lo, R., Y.-G. Chen, Y. Shi, N. Pavletich, and J. Massagué. 1998. The L3 loop: A structural motif determining specific interactions between SMAD proteins and TGF- $\beta$ receptors. EMBO J. 17: 996-1005.

Lyons, I., L. Parsons, L. Hartley, R. Li, J. Andrews, L. Robb, and R. Harvey. 1995. M yogenic and morphogenetic defects in the heart tubes of murine embryos lacking the homeo box gene Nkx2-5. Genes \& Dev. 9: 1654-1666.

Macias-Silva, M., S. Abdollah, P. Hoodless, R. Pirone, L. Attisano, and J. Wrana. 1996. MADR2 is a substrate of the TGF $\beta$ receptor and its phosphorylation is required for nuclear accumulation and signaling. Cell 87: 1215-1224.

Marques, G., M. Musacchio, M. Shimell, K. WunnenbergStapleton, K. Cho, and M. O'Connor. 1997. Production of a DPP activity gradient in the early Drosophila embryo through the opposing actions of the SOG and TLD proteins.
Cell 91: 417-426.

Mead, P., I. Brivanlou, C. Kelley, and L. Zon. 1996. BM P-4responsive regulation of dorsal-ventral patterning by the homeobox protein Mix.1. Nature 382: 357-360.

Nellen, D., M. Affolter, and K. Basler. 1994. Receptor serine/ threonine kinases implicated in the control of Drosophila body pattern by decapentaplegic. Cell 78: 225-237.

Nellen, D., R. Burke, G. Struhl, and K. Basler. 1996. Direct and long-range action of a DPP morphogen. Cell 85: 357-368.

N eumann, C. and S. Cohen. 1997. M orphogens and pattern formation. BioEssays 19: 721-729.

Onichtchouk, D., V. Gawantka, R. Dosch, H. Delius, K. Hirschfeld, C. Blumenstock, and C. N iehrs. 1996. The Xvent-2 homeobox gene is part of the BM P-4 signalling pathway controlling dorsoventral patterning of Xenopus mesoderm. Development 122: 3045-3053.

Padgett, R., R. St Johnston, and W. Gelbart. 1987. A transcript from a Drosophila pattern gene predicts a protein homologous to the transforming growth factor- $\beta$ family. Nature 325: 81-84.

Penton, A., Y. Chen, K. Staehling-Hampton, J. Wrana, L. Attisano, J. Szidonya, J. Cassill, J. Massagué, and F. Hoffmann. 1994. Identification of two bone morphogenetic protein type I receptors in Drosophila and evidence that Brk25D is a decapentaplegic receptor. Cell 78: 239-250.

Piccolo, S., Y. Sasai, B. Lu, and E. De Robertis. 1996. Dorsoventral patterning in Xenopus: Inhibition of ventral signals by direct binding of chordin to BM P-4. Cell 86: 589-598.

Raftery, L., V. Twombly, K. Wharton, and W. Gelbart. 1995. Genetic screens to identify el ements of the decapentaplegic signaling pathway in Drosophila. Genetics 139: 241-254.

Schmidt, J., G. von Dassow, and D. Kimelman. 1996. Regulation of dorsal-ventral patterning: The ventralizing effects of the novel Xenopus homeobox gene Vox. Development 122: 1711-1721.

Schultheiss, T., J. Burch, and A. Lassar. 1997. A role for bone morphogenetic proteins in the induction of cardiac myogenesis. Genes \& Dev. 11: 451-462.

Sekelsky, J., S. N ewfeld, L. Raftery, E. Chartoff, and W. Gel bart. 1995. Genetic characterization and cloning of mothers against dpp, a gene required for decapentaplegic function in Drosophila melanogaster. Genetics 139: 1347-1358.

Shi, Y., A. Hata, R. Lo, J. Massagué, and N. Pavletich. 1997. A structural basis for mutational inactivation of the tumour suppressor Smad4. Nature 388: 87-93.

St Johnston, R.D. and W.M. Gelbart. 1987. Decapentaplegic transcripts are localized along the dorsal-ventral axis of the Drosophila embryo. EMBO J. 6: 2785-2791.

Staehling-Hampton, K., F.M. Hoffmann, M.K. Baylies, E. Rushton, and M. Bate. 1994. dpp induces mesodermal gene expression in Drosophila. Nature 372: 783-786.

Staehling-Hampton, K., A. Laughon, and F. Hoffmann. 1995. A Drosophila protein related to the human zinc finger transcription factor PRDII/MBPI/HIV-EP1 is required for $d p p$ signaling. Development 121: 3393-3403.

Suzuki, A., C. Chang, J. Yingling, X. Wang, and A. HemmatiBrivanlou. 1997. Smad5 induces ventral fates in Xenopus embryo. Dev. Biol. 184: 402-405.

Thomsen, G. 1997. Antagonism within and around the organizer: BM P inhibitors in vertebrate body patterning. Trends Genet. 13: 209-211.

Tremml, G. and M. Bienz. 1992. Induction of Iabial expression in the Drosophila endoderm: Response elements for dpp signalling and for autoregulation. Development 116: 447-456.

Wharton, K.A., R.P. Ray, and W.M. Gelbart. 1993. An activity gradient of decapentaplegic is necessary for the specification 
Xu et al.

of dorsal pattern elements in the Drosophila embryo. Development 117: 807-822.

Wisotzkey, R.G., A. Mehra, D.J. Sutherland, L.L. Dobens, X. Liu, C. Dohrmann, L. Attisano, and L.A. Raftery. 1998. Medea is a Drosophila Smad4 homolog that is differentially required to potentiate DPP responses. Development 125: 1433-1445.

Yin, Z. and M. Frasch. 1998. Regulation and function of tinman during dorsal mesoderm induction and heart specification in Drosophila. Dev. Genet. 22: 187-200.

Yin, Z., X.-L. Xu, and M. Frasch. 1997. Regulation of the Twist target gene tinman by modular cis-regulatory elements during early mesoderm development. Development 124: 48714982.

Yingling, J., M. Datto, C. Wong, J. Frederick, N. Liberati, and X.-F. Wang. 1997. Tumor suppressor Smad4 is a transforming growth factor $\beta$-inducible DNA binding protein. Mol. Cell. Biol. 17: 7019-7028.

Zhang, Y., T. M usci, and R. Derynck. 1997. The tumor suppressor Smad4/DPC 4 as a central mediator of Smad function. Curr. Biol. 7: 270-276.

Zimmerman, L., J. De Jesus-Escobar, and R. Harland. 1996. The Spemann organizer signal noggin binds and inactivates bone morphogenetic protein 4. Cell 86: 599-606. 


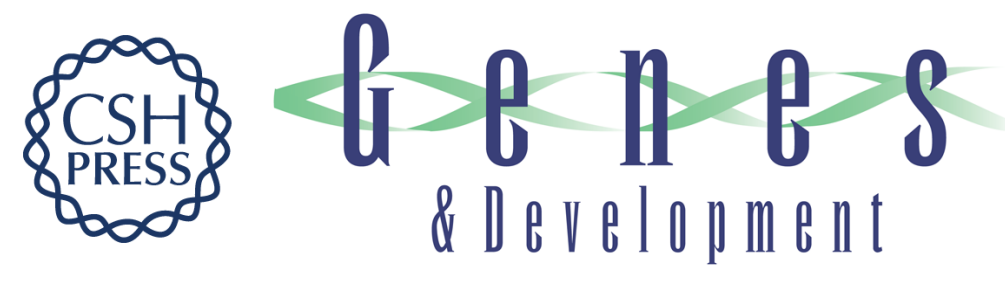

\section{Smad proteins act in combination with synergistic and antagonistic regulators to target Dpp responses to the Drosophila mesoderm}

Xiaolei Xu, Zhizhang Yin, John B. Hudson, et al.

Genes Dev. 1998, 12:

Access the most recent version at doi:10.1101/gad.12.15.2354

\section{License}

Email Alerting

Service

Receive free email alerts when new articles cite this article - sign up in the box at the top right corner of the article or click here.

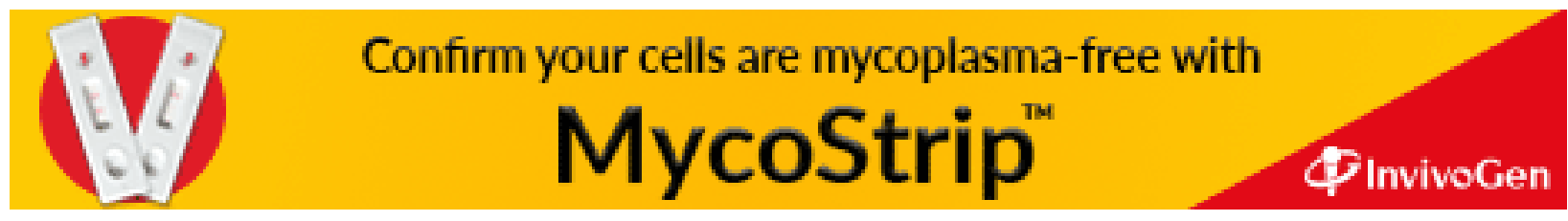

